\title{
Variation potential influence on photosynthetic cyclic electron flow in pea
}

\section{Vladimir Sukhov*, Lyubov Surova, Oksana Sherstneva, Lyubov Katicheva and Vladimir Vodeneev}

Department of Biophysics, N.I. Lobachevsky State University of Nizhny Novgorod, Nizhny Novgorod, Russia

\section{Edited by:}

Hartmut Stützel, Leibniz Universität Hannover, Germany

Reviewed by:

Albert Porcar-Castell, University of Helsinki, Finland

Wei Huang, Chinese Academy of Sciences, China

\section{${ }^{*}$ Correspondence:}

Vladimir Sukhov, Department of

Biophysics, N.I. Lobachevsky State University of Nizhny Novgorod,

Gagarin Avenue 23,

Nizhny Novgorod 603950, Russia

e-mail:vssuh@mail.ru
Cyclic electron flow is an important component of the total photosynthetic electron flow and participates in adaptation to the action of stressors. Local leaf stimulation induces electrical signals, including variation potential (VP), which inactivate photosynthesis; however, their influence on cyclic electron flow has not been investigated. The aim of this study was to investigate VP's influence on cyclic electron flow in pea (Pisum sativum L.). VP was induced in pea seedling leaves by local heating and measured in an adjacent, undamaged leaf by extracellular electrodes. $\mathrm{CO}_{2}$ assimilation was measured using a portable gas exchange measuring system. Photosystem I and II parameters were investigated using a measuring system for simultaneous assessment of P700 oxidation and chlorophyll fluorescence. Heating-induced VP reduced $\mathrm{CO}_{2}$ assimilation and electron flow through photosystem II. In response, cyclic electron flow rapidly decreased and subsequently slowly increased. Slow increases in cyclic flow were caused by decreased electron flow through photosystem II, which was mainly connected with VP-induced photosynthetic dark stage inactivation. However, direct influence by VP on photosystem I also participated in activation of cyclic electron flow. Thus, VP, induced by local leaf-heating, activated cyclic electron flow in undamaged leaves. This response was similar to photosynthetic changes observed under the direct action of stressors. Possible mechanisms of VP's influence on cyclic flow were discussed.

Keywords: cyclic electron flow, noncyclic electron flow, Pisum sativum, photosynthetic dark stage, photosystem I, photosystem II, variation potential

\section{INTRODUCTION}

Photosynthesis in plants is based on three light-driven electron flows, namely noncyclic, pseudocyclic, and cyclic flows (Allen, 2003). Cyclic electron flow is connected with photosystem I (PSI) and cytochrome $\mathrm{b}_{6} \mathrm{f}$ (Joliot and Joliot, 2006; Joliot and Johnson, 2011; Roach and Krieger-Liszkay, 2014), whereas other flows are also connected with photosystem II (PSII) (Allen, 2003; Roach and Krieger-Liszkay, 2014). In contrast to noncyclic and pseudocyclic electron flows, cyclic flow only yields ATP synthesis and does not generate NADPH for the Calvin cycle or reactive oxygen species (Allen, 2003).

Cyclic electron flow can be activated by different stressors and might serve as an adaptive mechanism (Bukhov et al., 1999; Rumeau et al., 2007; Zhang and Sharkey, 2009; Zivcak et al., 2013). In particular, under stress conditions, cyclic flow might regulate photosynthetic generation of reactive oxygen species (Zhang and Sharkey, 2009; Roach and Krieger-Liszkay, 2014), contribute to oxidation of the PSI acceptor side, thereby protecting it from damage (Rumeau et al., 2007; Roach and KriegerLiszkay, 2014), and support the transthylakoid proton gradient (Bukhov et al., 1999; Joliot and Joliot, 2006; Zhang and Sharkey, 2009). In turn, support of the $\mathrm{pH}$ gradient contributes to ATP synthesis, fluorescence non-photochemical quenching (NPQ), and thylakoid membrane stability (Zhang and Sharkey, 2009; Joliot and Johnson, 2011). Thus, it can be concluded (Roach and
Krieger-Liszkay, 2014) that activation of cyclic electron flow by the direct action of stressors plays an important role in adaptive responses in plants.

Local action by stressors induces electrical signals, namely action potential (AP) induced by non-damaging stimuli and variation potential (VP) caused by damaging stimuli, which propagate through the unstimulated parts of higher plants (Volkov, 2000; Dziubinska, 2003; Brenner et al., 2006; Mancuso and Mugnai, 2006; Stahlberg et al., 2006; Trebacz et al., 2006). Selfpropagating AP is mainly caused by fluxes of $\mathrm{Ca}^{2+}, \mathrm{K}^{+}$, and $\mathrm{Cl}^{-}$ ions (Felle and Zimmermann, 2007), while transient $\mathrm{H}^{+}$-ATPase inactivation and proton influx participate in its generation to a lesser degree (Sukhov and Vodeneev, 2009). VP generation is connected with transient plasmalemma $\mathrm{H}^{+}$-ATPase inactivation (Stahlberg et al., 2006); however, fluxes of $\mathrm{Ca}^{2+}, \mathrm{K}^{+}$, and $\mathrm{Cl}^{-}$ions might also participate in VP development (Vodeneev et al., 2011; Sukhov et al., 2013b; Katicheva et al., 2014). VP propagation is probably connected with transmission of hydraulic and/or chemical signals (Stahlberg et al., 2006; Trebacz et al., 2006; Vodeneev et al., 2012), which induce an electrical reaction.

Electrical signals can induce numerous functional responses (Dziubinska, 2003; Davies and Stankovic, 2006; Stahlberg et al., 2006; Volkov et al., 2008; Fromm and Lautner, 2012). In particular, they inactivate photosynthesis in unstimulated leaves (Koziolek et al., 2004; Krupenina and Bulychev, 2007; Grams 
et al., 2009; Pavlovič et al., 2011; Sukhov et al., 2012, 2013a, 2014a,b; Bulychev and Komarova, 2014). The first stage of photosynthetic response development is possibly ion influx. Investigations of Bulychev and coworkers (Krupenina and Bulychev, 2007) have shown that $\mathrm{Ca}^{2+}$ influx is a potential mechanism for AP influence on photosynthesis in Chara alga. In regard to VP, according to studies by Grams et al. (2009) and our previous investigations (Sukhov et al., 2013a, 2014a), plasmalemma $\mathrm{H}^{+}$-ATPase inactivation and subsequent proton influx are main mechanisms for VP influence on photosynthesis in higher plants.

Independent of mechanisms for initial photosyntheticresponse induction, subsequent development of this response is mainly connected with inactivation of the photosynthetic dark stage (Krupenina and Bulychev, 2007; Pavlovič et al., 2011; Pavlovič, 2012; Sukhov et al., 2012, 2014a,b), which decreases quantum yields of photosystem I and II and increases nonphotochemical fluorescence quenching. Influence of $\mathrm{Ca}^{2+}$ influx on photosynthetic dark stage can be connected (Krupenina and Bulychev, 2007) with the dependence of Calvin cycle enzymes on calcium concentrations in chloroplast stroma (Wolosiuk et al., 1993). Proton influx into cytoplasm and stroma can influence $\mathrm{CO}_{2}$ transport, changing carbonic anhydrase (Grams et al., 2009) and/or aquaporin (Gallé et al., 2013) activities and modifying the $\mathrm{CO}_{2} / \mathrm{HCO}_{3}^{-}$ratio (Bulychev et al., 2001). This influx might also reduce Calvin cycle activity (Wolosiuk et al., 1993). However, the direct influence of AP and VP on the light stage is also possible (Pavlovič et al., 2011; Sukhov et al., 2012, 2014a,b). The influence can be related to the rise of fluorescence non-photochemical quenching (Sukhov et al., 2014a) and reduced electron flow through the acceptor side of PSI (Sukhov et al., 2012), which might be caused by acidification of the stroma and lumen (Müller et al., 2001; Alte et al., 2010; Benz et al., 2010).

According to Retivin et al. (1997), rapid and transient increases in plant resistance to stressors (10-25 min after stimulation) are the final result of electrical signal-induced functional responses. The resistance increase in unstimulated parts of plant contributes to plant survival under systemic action of stressor which may follow after electrical signal induction (Retivin et al., 1997). Decrease of photosynthetic machinery damage can be a mechanism contributing to the influence of electrical signals on plant resistance to stressors (Sukhov et al., 2014b). AP (Retivin et al., 1999) and VP (Sukhov et al., 2014b) increase the resistance of photosynthetic machinery to the effects of temperature changes. Our previous results (Sukhov et al., 2014b) have shown that increased resistance of photosynthetic machinery to heat is caused by VPinduced inactivation of the photosynthetic dark stage. Changes in cyclic electron flow can link the VP-induced dark stage inactivation and photosynthetic machinery resistance increase (Sukhov et al., 2014b). However, experimental investigations of electrical signal influence on cyclic electron flow are lacking. Thus, the aim of the present study was to investigate VP influence on cyclic electron flow in pea (Pisum sativum L.).

\section{MATERIALS AND METHODS PLANT MATERIAL}

Seedlings of pea (Pisum sativum L.) were cultivated hydroponically in a Binder KBW 240-plant growth chamber (Binder
$\mathrm{GmbH}$, Tuttlingen, Germany) at $24^{\circ} \mathrm{C}$ under a $16 / 8 \mathrm{~h}$ (light/dark) photoperiod. Seedlings used in experiments were 14-21 days old.

\section{STIMULATION AND ELECTRICAL MEASUREMENTS}

VP was induced by heating $\sim 1 \mathrm{~cm}^{2}$ of a leaf tip (a stimulated leaf) over a flame for 3-4s, representing a standard damaging stimulus (Koziolek et al., 2004; Vodeneev et al., 2012; Sukhov et al., 2014a,b).

The surface electrical potential was measured using $\mathrm{Ag}^{+} / \mathrm{AgCl}$ electrodes (Gomel Plant of Measuring Equipment, Gomel, Belarus), a high-impedance amplifier IPL-113 (Semico, Novosibirsk, Russia) and a PC. Measurement electrodes contacted an unstimulated leaf via "Uniagel" conductive gel (Geltek-Medica, Moscow, Russia), according to our previous studies (Sukhov et al., 2014a,b). Electrical activity was monitored by two electrodes (Figure 1), with the first $\left(E_{S}\right)$ placed on a stem and the second $\left(E_{L}\right)$ connected with a leaflet center of an unstimulated leaf. The distance between the $E_{S}$ site and the damaged area was $6-7 \mathrm{~cm}$ and the distance between $E_{S}$ and $E_{L} 3-5 \mathrm{~cm}$. It should be noted that, as electrical responses in conjugate leaflets of a leaf were very similar in pea (Sukhov et al., $2014 a, b)$, the electrical reaction, registered by $E_{L}$, was used for investigation of VP parameters in conjugate leaflets in which photosynthesis was measured. The $E_{R}$ was placed in a standard solution surrounding the root.

\section{MEASUREMENTS OF PHOTOSYNTHETIC PARAMETERS}

Photosynthetic parameters in intact pea leaves were measured by a system composed of a GFS-3000 portable gas exchange measuring system, a Dual-PAM-100 measuring system for simultaneous assessment of P700 oxidation and chlorophyll fluorescence,

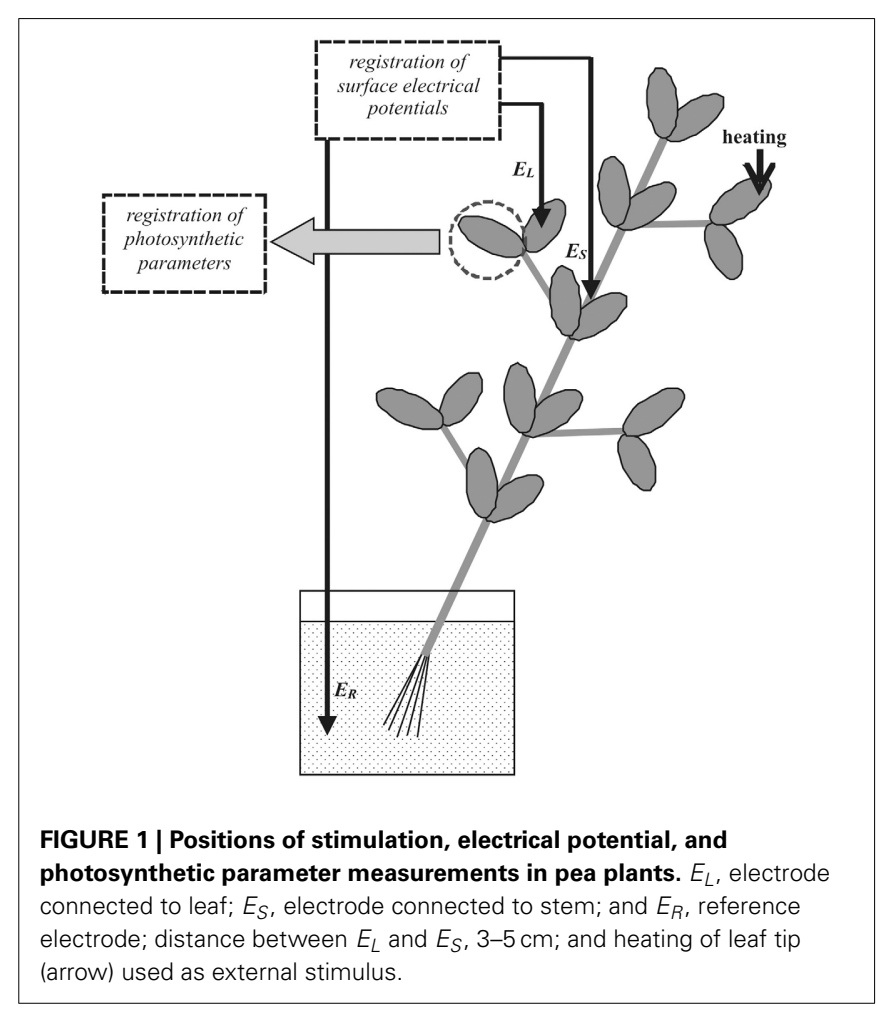


and a measuring head Dual-PAM gas exchange Cuvette 3010Dual (Heinz Walz GmbH, Effeltrich, Germany). The system was employed for simultaneous recording of photosynthetic dark and light stage parameters in unstimulated leaf lamina (measured area, $1.3 \mathrm{~cm}^{2}$ ).

The initial parameters of PSII fluorescence, the dark and maximal fluorescence yields ( $F_{0}$ and $F_{m}$, respectively), were measured after dark adaptation for $20 \mathrm{~min}$. The maximal change in the P700 signal $\left(P_{m}\right)$ of PSI, reflecting maximal P700 oxidation, was measured after preliminary illumination by far red light for $10 \mathrm{~s}$. The steady-state fluorescence yields in light $(F$ and $F_{m}^{\prime}$, respectively), and steady-state and maximal signals in light ( $P$ and $P_{m}^{\prime}$, respectively) were measured using saturation pulses generated every $10 \mathrm{~s}$. Quantum yields of PSI $\left(\phi_{P S I}\right)$, nonphotochemical energy dissipation in PSI because of donor side limitation $\left(\phi_{N D}\right)$, and non-photochemical energy dissipation in PSI connected with acceptor-side limitation $\left(\phi_{N A}\right)$ were calculated using the equations $\phi_{P S I}=\left(P_{m}^{\prime}-P\right) / P_{m}, \phi_{N D}=P / P_{m}$, and $\phi_{N A}=\left(P_{m}-P_{m}^{\prime}\right) / P_{m}$ (Klughammer and Schreiber, 2008). The effective quantum yield of PSII $\left(\phi_{P S I I}\right)$ and fluorescence non-photochemical quenching (NPQ) were calculated using the equations $\phi_{P S I I}=\left(F_{m}^{\prime}-F\right) / F_{m}^{\prime}$ and $N P Q=\left(F_{m}-F_{m}^{\prime}\right) / F_{m}^{\prime}$ (Maxwell and Johnson, 2000). The $\mathrm{CO}_{2}$ assimilation rate $(A$, $\mu \mathrm{mol} \mathrm{CO}_{2} \cdot \mathrm{m}^{-2} \cdot \mathrm{s}^{-1}$ ) was measured using the GFS-3000 system and its software, and the parameter programmatically calculated according to Von Caemmerer and Farquhar (1981).

The external $\mathrm{CO}_{2}$ concentration $\left(\left[\mathrm{CO}_{2}\right]\right)$ was $360 \mathrm{ppm}$ in the control and $\sim 10-15$ ppm under low $\left[\mathrm{CO}_{2}\right]$ conditions. In some series of experiments, $\mathrm{CO}_{2}$ concentration was decreased from $360 \mathrm{ppm}$ to $\sim 150$ or $\sim 10-15 \mathrm{ppm}$. Relative air humidity and leaf temperature were $\sim 60 \%$ and $\sim 23^{\circ} \mathrm{C}$, respectively. Blue actinic light $(460 \mathrm{~nm})$ intensity in the control was $239 \mu \mathrm{mol} \cdot \mathrm{m}^{-2} \cdot \mathrm{s}^{-1}$. In a separate experimental series, far red light $\left(240 \mu \mathrm{mol} \cdot \mathrm{m}^{-2} \cdot \mathrm{s}^{-1}\right.$, $730 \mathrm{~nm}$ ) was used as actinic light.

$\mathrm{VP}$ was induced in plants $\sim 1 \mathrm{~h}$ after initiation of actinic light, and photosynthetic responses monitored for $30 \mathrm{~min}$.

\section{CALCULATIONS OF ELECTRON FLOWS}

Electron flows through PSI $[E F(P S I)]$ and PSII $[E F(P S I I)]$ were calculated using Equations (1) and (2) (Miyake et al., 2004, 2005; Huang et al., 2012; Zivcak et al., 2013):

$$
\begin{gathered}
E F(P S I)=\alpha_{I} \times \phi_{P S I} \times P F D, \\
E F(P S I I)=\alpha_{I I} \times \phi_{P S I I} \times P F D,
\end{gathered}
$$

where $P F D$ was the photosynthetically-active photon flux density of light illuminating a leaf, $\alpha_{I}=p \times(1-d I I)$ and $\alpha_{I I}=p \times d I I$ the fractions of photon flux distributed to PSI and PSII, $d I I$ the fraction of absorbed light distributed to PSII, and $p$ the fraction of PFD absorbed by leaves.

The electron flow through PSI included noncyclic, pseudocyclic, and cyclic flows, whereas the electron flow through PSII included only noncyclic and pseudocyclic flows (Allen, 2003). Thus, cyclic electron flow $[E F(C)]$ is described as Equation (3) (Miyake et al., 2004, 2005; Huang et al., 2012; Zivcak et al., 2013):

$$
E F(C)=E F(P S I)-E F(P S I I)
$$

Calculation of $E F(C)$ required values for $p$ and $d I I$ [Equations (1)-(3)]. The value of $p$ was measured according to Berger et al. (2004), using a standard procedure in IMAGING-PAM M-Series MINI Version (Heinz Walz $\mathrm{GmbH}$ ) and found to be $0.88 \pm 0.01$ $(n=10)$.

According to a number of studies (Miyake and Yokota, 2000; Makino et al., 2002; Miyake et al., 2004, 2005), the fraction of absorbed light distributed to PSII was calculated on the basis of the Farquhar, Von Caemmerer and Berry photosynthetic model of Von Caemmerer et al. (2009). According to this model, $\mathrm{CO}_{2}$ assimilation $(A)$ under electron transport limited conditions is described by the Equation (4):

$$
A=\frac{\left(C_{c}-\Gamma^{*}\right)}{4\left(C_{c}+2 \Gamma^{*}\right)} \times E F(P S I I)-R_{d},
$$

where $\Gamma^{*}$ is the photosynthetic $\mathrm{CO}_{2}$ compensation point in the absence of mitochondrial respiration (36.9-39.6 ppm), $R_{d}$ the respiration rate in darkness, and $C_{c}$ the mole fraction of $\mathrm{CO}_{2}$ in chloroplasts. Under high $\left[\mathrm{CO}_{2}\right]\left(\mathrm{C}_{c} \rightarrow \infty\right)$ Equation (4) transforms to Equation (5):

$$
E F(P S I I)=4\left(A+R_{d}\right)
$$

Combining Equations (1) and (3) yields:

$$
d I I=\frac{4\left(A+R_{d}\right)}{p \times \phi_{P S I I} \times P F D},
$$

Equation (6) was in good accordance with the works of Miyake et al. (2004); Miyake et al. (2005). Figure 2A shows dII calculated under different PFDs and an external $\left[\mathrm{CO}_{2}\right]$ of $2000 \mathrm{ppm}$. This condition was electron transport limited because $A+R_{d}$ depended on PFD in a linear manner. The value of $d I I$ varied from 0.40 to 0.44 and was not significantly dependent on light intensity $(p>0.05)$.

For the purpose of additional $d I I$ control, an alternative method for measuring $d I I$ was used (Huang et al., 2012) that was simpler than the previous method. It is known that plants have slight cyclic electron flow under low light intensity and that flow magnitude increases with increasing PFD (Miyake et al., 2005; Joliot and Joliot, 2006; Huang et al., 2011; Zivcak et al., 2013). Therefore, $E F(P S I)$ approximately equals $E F(P S I I)$ under low light condition (Huang et al., 2012). Taking into account that $E F(P S I)=E F(P S I I)$ and using Equations (1) and (2), Equation (7) was deduced:

$$
d I I=\frac{1}{\phi_{P S I I} / \phi_{P S I}+1} .
$$

Figure $2 \mathrm{~B}$ shows that $d I I$ equaled $\sim 0.42$ under low light conditions $\left(P F D \leq 65 \mu \mathrm{mol} \cdot \mathrm{m}^{-2} \cdot \mathrm{s}^{-1}\right)$. Increases in $d I I$ were observed under light intensity equaling $108 \mu \mathrm{mol} \cdot \mathrm{m}^{-2} \cdot \mathrm{s}^{-1}$ and greater. This increase probably reflected increased cyclic electron flow, i.e., $E F(P S I) \neq E F(P S I I)$ under moderate and high light conditions. Thus, Equation (7) could also be used for $d I I$ calculation under low actinic light $\left(\leq 65 \mu \mathrm{mol} \cdot \mathrm{m}^{-2} \cdot \mathrm{s}^{-1}\right)$. 
Values for $d I I$ calculated after a $1 \mathrm{~h}$ illumination by control actinic light $\left(239 \mu \mathrm{mol} \cdot \mathrm{m}^{-2} \cdot \mathrm{s}^{-1}\right)$ were in accordance with the time of VP induction. However, dII might have depended on the duration of actinic light illumination, which could have influenced results. Values of $d I I$ decreased from about 0.510.53 to $\sim 0.41-0.46$ with increased light duration $\left(t_{1 / 2}=20 \mathrm{~min}\right.$, Figure 2C), but it was essentially unchanged from the 60th to 100th min; i.e., $d I I$ was constant in the range of photosynthetic response investigated here.

Initial $d I I$ changes could have been connected with a statetransition and/or PSII damage. State-transition relaxation duration is from minutes to tens of minutes and damage relaxation time in hours (Maxwell and Johnson, 2000; Müller et al., 2001). As a result, state-transition might have been altered under VP rather than with PSII damage. Analysis of $F_{m}^{\prime}$ relaxation kinetics in darkness after $1 \mathrm{~h}$ of actinic light illumination showed that there were insignificant changes in this parameter from the 5 th to 40th min (Figure 2D); i.e., there was no essential state-transition under these experimental conditions. In addition, this result supported the observed $d I I$ stability in the time range of VP-induced photosynthetic responses. Thus, taking into account these results, a $d I I$ value of 0.42 was used in the present work.

Far red light, which is absorbed predominantly by PSI, was used as actinic light in an individual series of experiments. In this case, EF(PSII) was also described by Equation (1); however, far red light absorption by PSII, which is low (Joliot and Johnson, 2011), was assumed equal to zero and PFD to be small $\left(5 \mu \mathrm{mol} \cdot \mathrm{m}^{-2} \cdot \mathrm{s}^{-1}\right.$, measuring light). Here, $E F(P S I)$ was described by Equation (8):

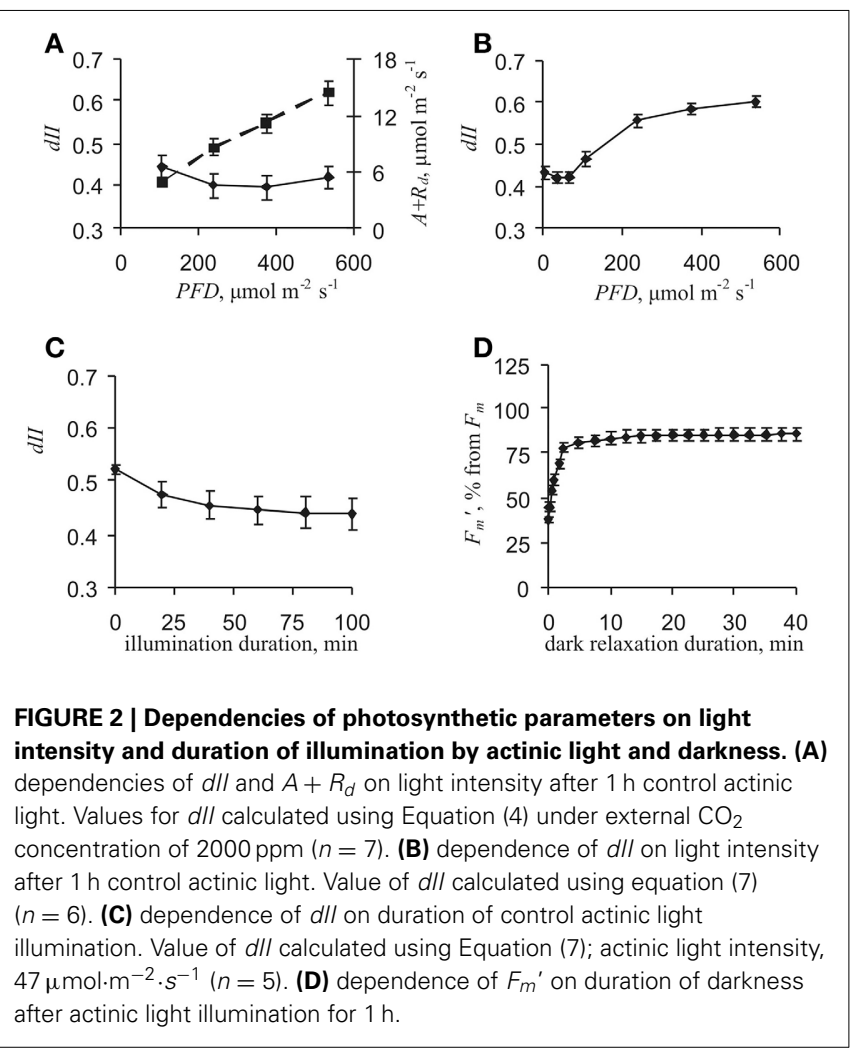

$$
E F(P S I)=p \times(1-d I I) \times \phi_{P S I} \times(P F D+F R F D \times \delta),
$$

where FRFD was the far red light flux density, $\delta$ the ratio of far red light to actinic light absorption by leaf $(730$ and $460 \mathrm{~nm}$, respectively), $P F D=5 \mu \mathrm{mol} \cdot \mathrm{m}^{-2} \cdot \mathrm{s}^{-1}$, and $\delta$ has been calculated from green leaf absorption spectra (Hogewoning et al., 2012) and equaled $\sim 0.12$.

Relative $E F(C)$ was also used in analyses, as the percentage of cyclic electron flow in the total flow. Relative $E F(C)$ was calculated using Equation (9):

$$
\text { relative } E F(C)=\frac{E F(C)}{E F(C)+E F(P S I I)} \times 100 \% .
$$

\section{STATISTICS}

Each series of experiments comprised 5-17 measurements, with each measurement performed on a separate plant. Representative records, obtained for individual measurements, mean values, standard errors, and correlation coefficients, are presented in the accompanying figures and tables. Significant differences in experiments were indicated according to the paired Student's $t$-test.

\section{RESULTS}

\section{PHOTOSYNTHETIC RESPONSES INDUCED BY VARIATION POTENTIAL}

Local heating of a leaf induced VP propagation through the stem (Figure 3A). The signal amplitude was $40-90 \mathrm{mV}$, the duration wide-ranging (from 5 to $60 \mathrm{~min}$ ), and the profile varied. In the most experiments $(\sim 80 \%)$, VP propagated into leaf lamina with an amplitude of $20-75 \mathrm{mV}$, with propagation velocities between steam and leaf at $0.02-$ $0.20 \mathrm{~cm} \cdot \mathrm{s}^{-1}$. In some experiments $(\sim 20 \%)$, only electrical reactions with small amplitude $(<15 \mathrm{mV})$ were observed in lamina (Figure 3B).

Figure 4 and Table 1 show that VP reduced $\mathrm{CO}_{2}$ assimilation rates and electron flows through PSII, increased NPQ and $\phi_{N D}$, and weakly decreased $\phi_{N A}$. The response of $E F(C)$ comprised two stages: fast inactivation of cyclic flow $\left(E F(C)_{\min }\right.$ - $\left.E F(C)_{\text {initial }}\right)$ and a following slow activation $\left(E F(C)_{\max }\right.$ $\left.E F(C)_{\text {min }}\right)$. Extremes of $E F(P S I I)$ decrease, $E F(C)$ fast inactivation, and $\operatorname{EF}(C)$ slow activation were observed at $2.8 \pm 0.3$,

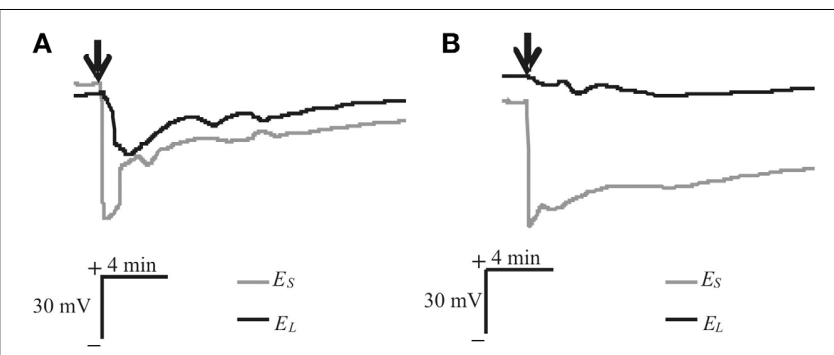

FIGURE 3 | Heat-induced changes in surface electrical potentials of steam and leaf. (A) VP propagated into leaf $(n=17)$. (B) Only electrical reactions of small amplitude $(<15 \mathrm{mV})$ propagated into leaf $(n=4)$. VP induced by heating tip of another leaf (arrow), and $E_{S}$ and $E_{L}$, changes in electrical potential measured by electrodes on stem and lamina, respectively. 

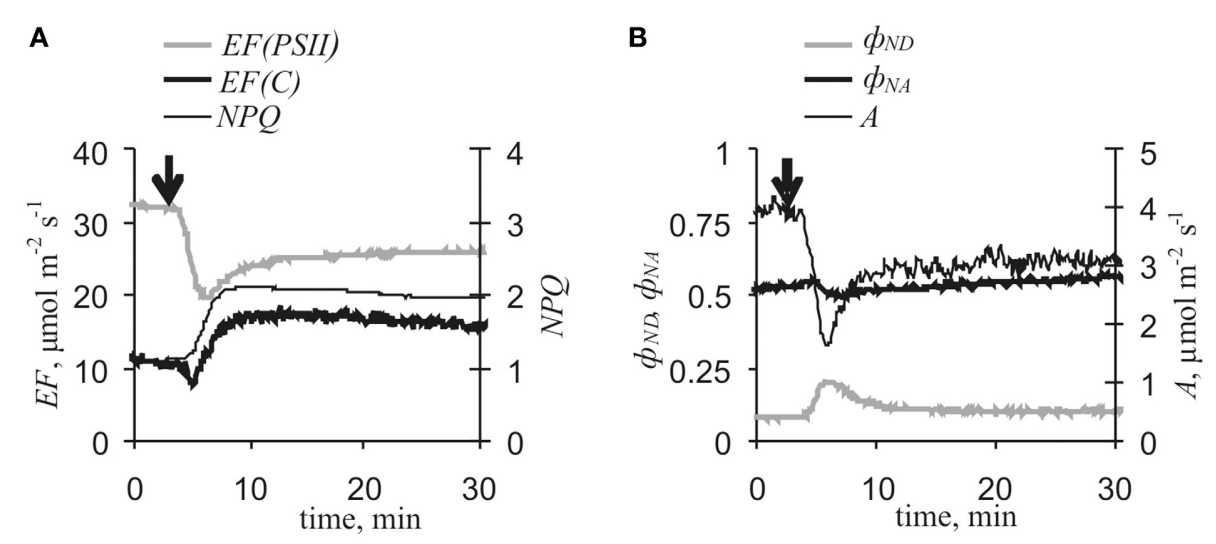

FIGURE 4 | Variation potential-induced changes in photosynthetic light stage parameters and $\mathrm{CO}_{2}$ assimilation under control conditions $(\boldsymbol{n}=17)$. (A) $E F(P S I I), E F(C)$ and $N P Q$. (B) $\phi_{N D}, \phi_{N A}$, and $A$. Arrow, VP induction by local heating.

Table 1 | Photosynthetic parameters and changes induced by VP and $\left[\mathrm{CO}_{2}\right]$-lowering.

\begin{tabular}{|c|c|c|c|c|}
\hline & $\begin{array}{c}\text { VP under } \\
{\left[\mathrm{CO}_{2}\right]=360 \mathrm{ppm}}\end{array}$ & $\begin{array}{c}{\left[\mathrm{CO}_{2}\right]-} \\
\text { lowering to } 10-15 \mathrm{ppm}\end{array}$ & $\begin{array}{l}{\left[\mathrm{CO}_{2}\right]-} \\
\text { lowering to } 150 \mathrm{ppm}\end{array}$ & $\begin{array}{c}\text { VP under } \\
{\left[\mathrm{CO}_{2}\right]=10-15 \mathrm{ppm}}\end{array}$ \\
\hline$n$ & 17 & 9 & 10 & 11 \\
\hline$E F(P S I I)_{\text {initial }}, \mu \mathrm{mol} \cdot \mathrm{m}^{-2} \cdot \mathrm{s}^{-1}$ & $30.1 \pm 1.2$ & $33.1 \pm 2.2$ & $34.3 \pm 1.3$ & $13.7 \pm 1.4$ \\
\hline$E F(P S I I)_{\min }, \mu \mathrm{mol} \cdot \mathrm{m}^{-2} \cdot \mathrm{s}^{-1}$ & $23.6 \pm 1.1^{*}$ & $13.5 \pm 1.6^{*}$ & $25.9 \pm 1.1^{*}$ & $8.1 \pm 1.0^{*}$ \\
\hline$E F(C)_{\min }, \mu \mathrm{mol} \cdot \mathrm{m}^{-2} \cdot \mathrm{s}^{-1}$ & $8.6 \pm 1.2^{*}$ & $11.7 \pm 2.3$ & $11.1 \pm 1.8$ & $15.0 \pm 1.2^{*}$ \\
\hline$E F(C)_{\max }, \mu \mathrm{mol} \cdot \mathrm{m}^{-2} \cdot \mathrm{s}^{-1}$ & $14.4 \pm 1.1^{*}$ & $20.0 \pm 1.6^{*}$ & $15.3 \pm 2.1^{*}$ & $18.6 \pm 1.3$ \\
\hline$E F(C)_{\min }-E F(C)_{\text {initial }}, \mu \mathrm{mol} \cdot \mathrm{m}^{-2} \cdot \mathrm{s}^{-1}$ & $-2.6 \pm 0.3^{*}$ & 0 & $-0.2 \pm 0.1$ & $-3.1 \pm 0.4^{*}$ \\
\hline$E F(C)_{\max }-E F(C)_{\min }, \mu \mathrm{mol} \cdot \mathrm{m}^{-2} \cdot \mathrm{s}^{-1}$ & $5.8 \pm 0.4^{*}$ & $8.3 \pm 1.1^{*}$ & $4.2 \pm 0.5^{*}$ & $3.6 \pm 0.5^{*}$ \\
\hline$N P Q_{\text {initial }}$ & $1.16 \pm 0.05$ & $1.25 \pm 0.14$ & $1.29 \pm 0.09$ & $2.76 \pm 0.14$ \\
\hline$\phi_{N D \max }-\phi_{N D \text { initial }}$ & $0.061 \pm 0.008^{*}$ & $0.111 \pm 0.010^{*}$ & $0.035 \pm 0.006^{*}$ & $0.051 \pm 0.009 *$ \\
\hline$\phi_{N A \text { initial }}$ & $0.584 \pm 0.015$ & $0.559 \pm 0.027$ & $0.563 \pm 0.027$ & $0.536 \pm 0.028$ \\
\hline$\phi_{N A \min }$ & $0.572 \pm 0.014^{*}$ & $0.531 \pm 0.025^{*}$ & $0.551 \pm 0.028^{*}$ & $0.549 \pm 0.026$ \\
\hline$\phi_{N A \min }-\phi_{N A i n i t i a l}$ & $-0.012 \pm 0.002^{*}$ & $-0.029 \pm 0.007^{*}$ & $-0.012 \pm 0.003^{*}$ & $0.013 \pm 0.006$ \\
\hline
\end{tabular}

${ }^{*} p<0.05$ compared with control, paired Student t-test.

$1.0 \pm 0.1$ and $5.9 \pm 0.3 \mathrm{~min}$, respectively, after the start of photosynthetic responses. Fast inactivation and slow activation were probably independent of each other under control conditions because the correlation coefficient $(r)$ between $E F(C)_{\min }$ $E F(C)_{\text {initial }}$ and $E F(C)_{\max }-E F(C)_{\min }$ was $-0.07(p>0.05)$. If only electrical reactions with small amplitudes $(<15 \mathrm{mV})$ were observed in leaf lamina, a photosynthetic response was not developed.

Responses in $E F(C)$ might have been connected with VPinduced changes in $d I I$. The method for $d I I$ calculation by Huang et al. (2012) could not be used for plants that were stressed after local heating. However, $d I I$ changes must have modified $F_{m}^{\prime}$ under dark conditions. VP's influence on $F_{m}^{\prime}$ without actinic light was investigated here. It was shown that VP induced only small decrease of $F_{m}^{\prime}(3 \pm 1 \%, n=5)$, i.e., VP weakly influence dII.

Inactivation of the photosynthetic dark stage is an initial process of VP-induced photosynthetic responses in pea (Sukhov et al., 2014a,b) and geranium (Sukhov et al., 2012). The present results showed that VP-induced $A$ and $E F(P S I I)$ decreases were strongly correlated $(r=0.78, p<0.001)$. Artificial reduction of dark stage activity through lowering of external $\left[\mathrm{CO}_{2}\right]$ decreased $E F(P S I I)$ and increased $E F(C), \phi_{N D}$ and $N P Q$ (Figure 5), but fast inactivation of cyclic flow was absent. Moreover, VP-induced decreases in $A$ and $E F(P S I I)$, increases in $\phi_{N D}$ and $N P Q$, 

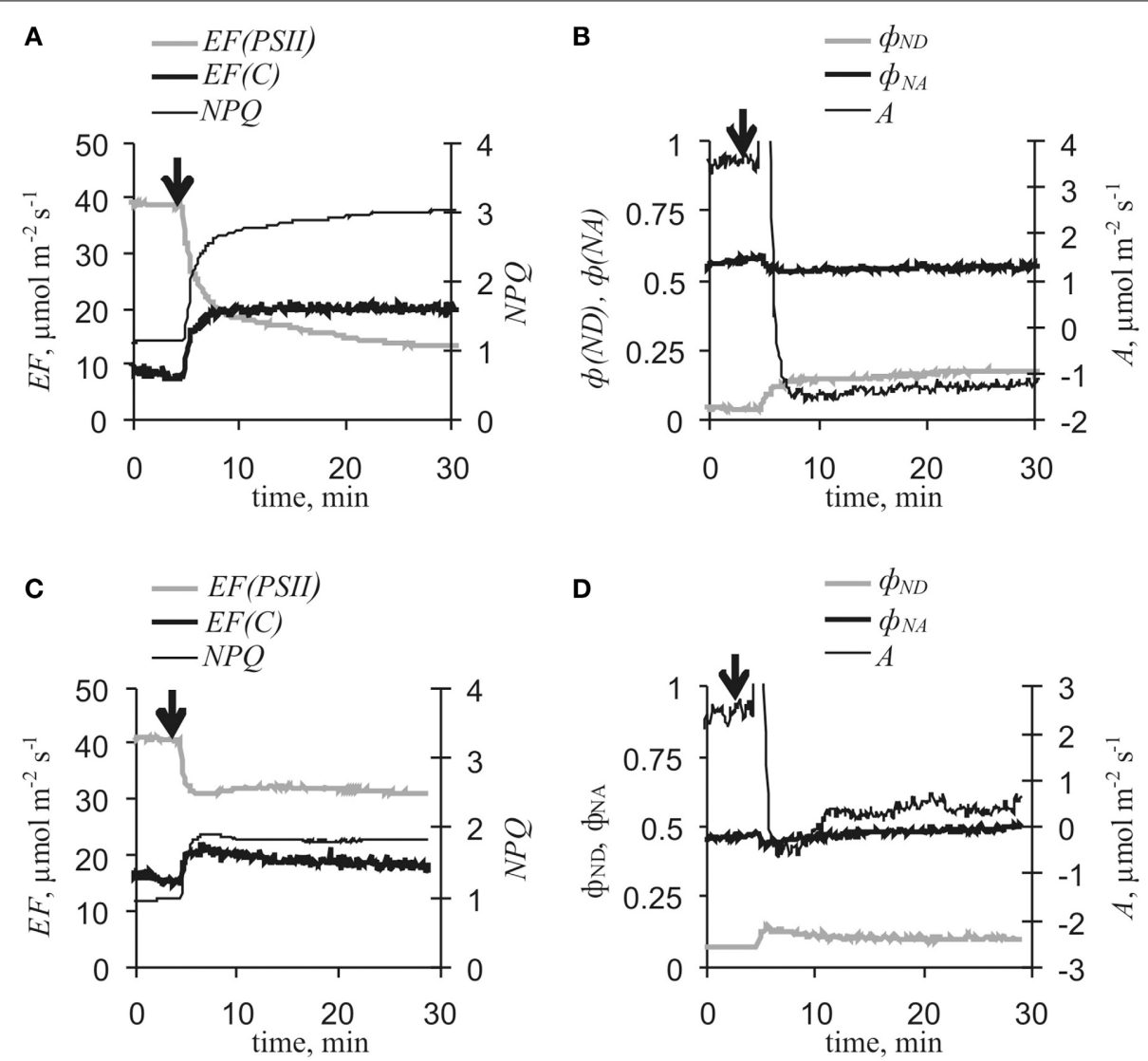

FIGURE 5 | $\left[\mathrm{CO}_{2}\right]$-lowering-induced changes in photosynthetic light stage parameters and $\mathbf{C O}_{\mathbf{2}}$ assimilation ( $\left.\boldsymbol{n}=\mathbf{9}-\mathbf{1 0}\right)$. (A) $E F(P S I I), E F(C)$ and $N P Q$ under $\left[\mathrm{CO}_{2}\right]$-lowering to $10-15 \mathrm{ppm}$. (B) $\phi_{N D}, \phi_{N A}$, and $A$ under

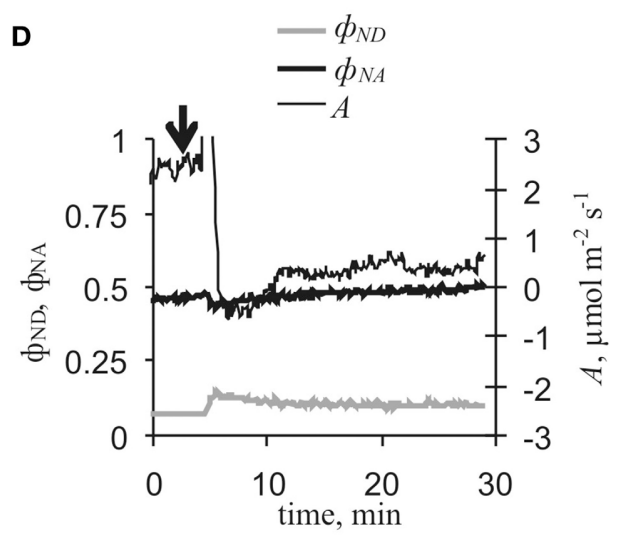

$\left[\mathrm{CO}_{2}\right]$-lowering to $10-15 \mathrm{ppm}$. (C) EF(PSII), EF(C) and NPQ under $\left[\mathrm{CO}_{2}\right]$-lowering to $150 \mathrm{ppm}$. (D) $\phi_{N D}, \phi_{N A}$, and $A$ under $\left[\mathrm{CO}_{2}\right]$-lowering to $150 \mathrm{ppm}$. Initial $\left[\mathrm{CO}_{2}\right]$ was $360 \mathrm{ppm}$. Arrow, start of $\left[\mathrm{CO}_{2}\right]$-lowering.

and slow activation of $E F(C)$ were collectively smaller under low $\left[\mathrm{CO}_{2}\right]$ conditions $(10-15 \mathrm{ppm})$ than under control conditions (Figure 6, Table 1). In particular, maximum cyclic flow after VP was not distinguishable from the flow before electrical signal propagation under these conditions. However, fast inactivation of cyclic flow induced by VP under low $\left[\mathrm{CO}_{2}\right]$ was not significantly different from the controls. It should be noted that the correlation coefficient between $\mathrm{EF}(\mathrm{C})_{\min }$ $\mathrm{EF}(\mathrm{C})_{\text {initial }}$ and $\mathrm{EF}(\mathrm{C})_{\max }-\mathrm{EF}(\mathrm{C})_{\min }$ was $-0.81(p<0.01)$ under low $\left[\mathrm{CO}_{2}\right]$.

\section{CORRELATION ANALYSIS OF THE MECHANISM OF VP-INDUCED CYCLIC ELECTRON FLOW CHANGES}

Changes in $E F(P S I I)$ and $E F(C)$ might be different stages of united $\mathrm{VP}$-induced photosynthetic response. This hypothesis was tested by analysis that revealed correlations between photosynthetic parameter changes (Table 2). There were strong connections between VP or $\left[\mathrm{CO}_{2}\right]$-lowering-induced reduction of electron flow through PSII and slow activation of cyclic electron flow under control initial conditions. Correlation between decreases in $E F(P S I I)$ and fast inactivation of $E F(C)$ was insignificant. Under low $\left[\mathrm{CO}_{2}\right]$, VP-induced responses of $E F(P S I I)$ and $E F(C)$ were weakly connected with each other.
The connection between $E F(P S I I)$ decrease and slow $E F(C)$ activation might have been caused by changes in $\phi_{N D}$. Really, correlation analysis showed that electron flow reductions through PSII induced by VP or $\left[\mathrm{CO}_{2}\right]$-lowering was strongly correlated with increases in $\phi_{N D}$ (Table 2). Conversely, $\phi_{N D}$ increases were correlated with slow cyclic electron flow activation under control initial conditions, but the correlation coefficient was insignificant for VP-induced responses under initial low $\left[\mathrm{CO}_{2}\right]$.

\section{VP-INDUCED CYCLIC ELECTRON FLOW CHANGES UNDER FAR RED LIGHT}

Far red light selectively activates PSI and is widely used for cyclic electron flow investigations (Joliot and Johnson, 2011). Here, far red light conditions were used for more detailed investigation of VP's influence on cyclic electron flow, and Figure 7 and Table 3 show VP-induced photosynthetic responses under far red light. VP decreased $A, E F(P S I I)$, and $\phi_{N D}$ and increased $\phi_{N A}$ and NPQ. VP-induced changes in $E F(C)$ included two stages as described above, inactivation and subsequent activation. Both activation and inactivation were weakly connected with decreased electron flow through PSII. Correlation between $E F(P S I I)$ and $\phi_{N D}$ decreases was also insignificant. Conversely, slow $E F(C)$ activation was strongly correlated with decreased $\phi_{N D}$. Connections 

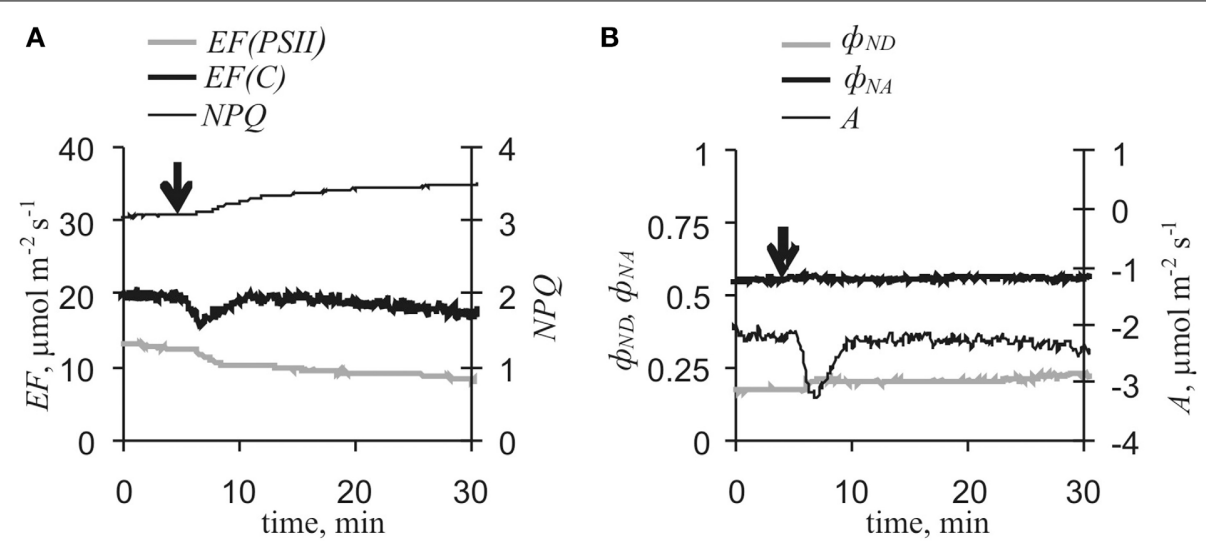

FIGURE 6 | Variation potential-induced changes in photosynthetic light stage parameters and $\mathrm{CO}_{2}$ assimilation under low $\left[\mathrm{CO}_{2}\right]$ conditions $(n=11)$. (A) $E F(P S I), E F(C)$ and $N P Q$. (B) $\phi_{N D}, \phi_{N A}$, and $A$. $\left[\mathrm{CO}_{2}\right]$ was $10-15 \mathrm{ppm}$. Arrow, VP induction by local heating.

Table 2 | Correlation coefficients between changes in photosynthetic parameters induced by VP and $\left[\mathrm{CO}_{2}\right]$-lowering.

\begin{tabular}{|c|c|c|c|}
\hline Parameters & $\begin{array}{l}\text { VP under } \\
{\left[\mathrm{CO}_{2}\right]=} \\
360 \mathrm{ppm}\end{array}$ & $\begin{array}{c}{\left[\mathrm{CO}_{2}\right]-} \\
\text { lowering to } \\
10-15 \text { or } 150 \mathrm{ppm}\end{array}$ & $\begin{array}{l}\text { VP under } \\
{\left[\mathrm{CO}_{2}\right]=} \\
10-15 \mathrm{ppm}\end{array}$ \\
\hline$n$ & 17 & 19 & 11 \\
\hline $\begin{array}{l}E F(P S I I)_{\text {min }}-E F(P S I I)_{\text {initial }} \\
\text { and } \\
E F(C)_{\text {min }}-E F(C)_{\text {initial }}\end{array}$ & 0.11 & - & -0.15 \\
\hline $\begin{array}{l}E F(P S I I)_{\min }-E F(P S I I)_{\text {initial }} \\
\text { and } \\
E F(C)_{\text {max }}-E F(C)_{\min }\end{array}$ & $-0.89 *$ & $-0.85^{*}$ & -0.04 \\
\hline $\begin{array}{l}E F(P S I I)_{\min }-E F(P S I I)_{\text {initial }} \\
\text { and } \\
\phi_{N D \text { max }}-\phi_{\text {NDinitial }}\end{array}$ & $-0.90^{*}$ & $-0.90^{*}$ & -0.73 \\
\hline $\begin{array}{l}\phi_{N D} \max \\
\text { and } \\
E F(C)_{\max }-E F(C)_{\min }\end{array}$ & $0.80^{*}$ & $0.77^{*}$ & -0.20 \\
\hline
\end{tabular}

${ }^{*}$ Correlation coefficient is significant $(p<0.05)$, Student t-test.

of changes in $\phi_{N A}$ with decreases in $E F(P S I I)$ and increases in $E F(C)$ were insignificant (data not shown). It should be noted that there was a tenuous connection between $E F(C)_{\text {min }}-E F(C)_{\text {initial }}$ and $E F(C)_{\max }-E F(C)_{\min }$ under far red light conditions $(r=-0.65, p=0.06)$.

\section{VP- AND [ $\mathrm{CO}_{2}$ ]-LOWERING-INDUCED INCREASES IN RELATIVE CYCLIC ELECTRON FLOW}

Examination of changes in relative cyclic electron flow induced by VP or $\left[\mathrm{CO}_{2}\right]$-lowering showed that, with VP under control, low $\left[\mathrm{CO}_{2}\right]$, and far red light conditions as well as decreased $\left[\mathrm{CO}_{2}\right]$ alone induced increases in relative electron flow (Table 4). This effect was observed even if the absolute $E F(C)$ showed no changes (photosynthetic response induced by VP under low $\left[\mathrm{CO}_{2}\right]$ ).

Stimulation of NPQ is mechanism of cyclic electron flow influences on plant resistance to stressors (Zhang and Sharkey, 2009; Joliot and Johnson, 2011). NPQ has been plotted against relative
$E F(C)$ under different $\mathrm{CO}_{2}$ concentrations (Figure 8). $E F(C)$ and NPQ were taken from the Tables 1, 4 (unheated plants). Figure 8 shows that $E F(C)$ and NPQ were linearly connected.

Connection between relative cyclic electron flow and fluorescence non-photochemical quenching were observed under control conditions too. Correlation coefficient between $E F(C)$ and NPQ was $0.64(n=36 . p<0.001)$.

\section{DISCUSSION}

Electrical signals can inactivate photosynthesis in plants (Koziolek et al., 2004; Krupenina and Bulychev, 2007; Grams et al., 2009; Pavlovič et al., 2011; Sukhov et al., 2012, 2013a, 2014a,b). In particular, VP reduces $\phi_{P S I}, \phi_{P S I}$, and $\mathrm{A}$, and increases NPQ in pea (Sukhov et al., 2014a,b). Inactivation of the photosynthetic dark stage appears to be the initiator of photosynthetic responses induced by AP (Pavlovič et al., 2011) and VP (Sukhov et al., 2012, 2014a,b). However, direct influence of electrical signals on PSI (Sukhov et al., 2012) and PSII (Pavlovič et al., 2011; Sukhov et al., $2014 a, b)$ is also observed.

Our results showed that VP, propagating into a leaf (Figure 3), induced changes in photosynthetic electron flows (Figure 4). VPinduced $E F(P S I I)$ decreases were in good accordance with data regarding $\phi_{P S I}$ decreases caused by electrical signals (see above). However, changes in $E F(C)$, which included fast cyclic electron flow inactivation and its subsequent slow activation, were not previously shown and required detailed analysis.

Here, $d I I$ was shown to be stable in the range of photosynthetic response investigated (Figure $\mathbf{2 C}$ ), and a state-transition was insignificant under these experimental conditions (Figure 2D). Also, VP weakly influenced $F_{m}$ without actinic light and, therefore, slightly changed $d I I$. These results revealed that the $E F(C)$ response was not connected with $d I I$ changes.

Slow cyclic electron transport activation induced by VP and $\left[\mathrm{CO}_{2}\right]$-lowering was observed to be connected with decreased $E F(P S I I)$ and that this connection was mediated by increased $\phi_{N D}$ (Table 2). Low activity of the photosynthetic dark stage and noncyclic electron flow are known to be accompanied by high $E F(C)$ (Joliot and Joliot, 2006) as well as $\phi_{N D}$ value is positively correlated with cyclic flow magnitude (Munekage et al., 
A
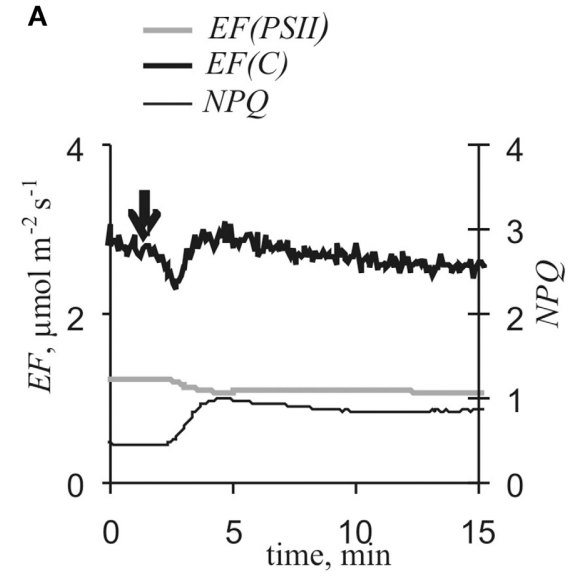

B
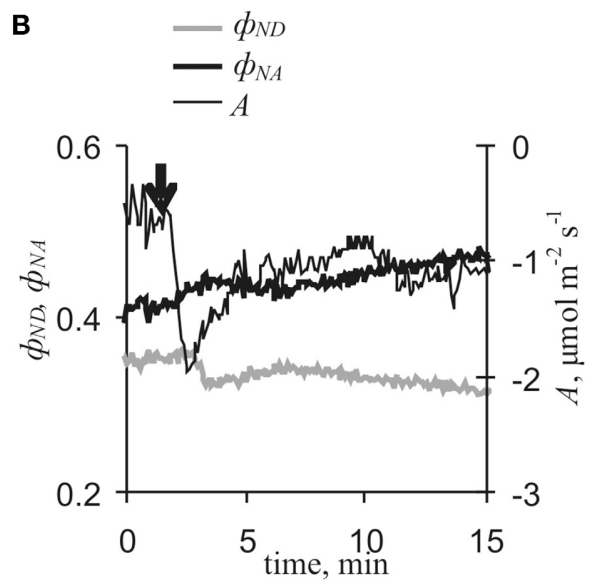

FIGURE 7 | Variation potential-induced changes in photosynthetic light stage parameters and $\mathrm{CO}_{\mathbf{2}}$ assimilation under far red light conditions $(\boldsymbol{n}=\mathbf{9}$ ). (A) $E F(P S I I), E F(C)$ and NPQ. (B) $\phi_{N D}, \phi_{N A}$, and A. Arrow, VP induction by local heating.

Table 3 | Photosynthetic parameters and changes induced by VP and correlation coefficients under far red light conditions.

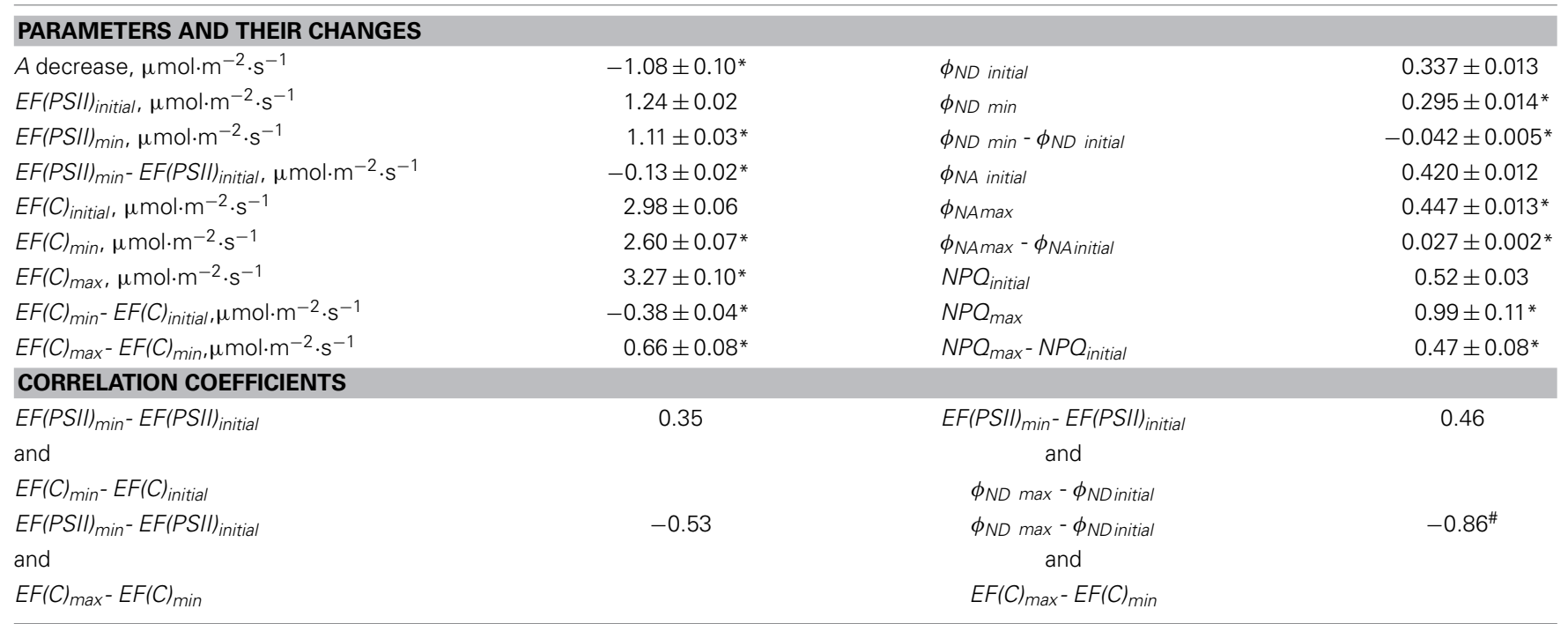

${ }^{*} p<0.05$ compared with control, paired Student $t$-test $(n=9)$.

\# Correlation coefficient is significant $(p<0.05)$, Student t-test.

Table 4 | Relative cyclic electron flow and changes induced by VP and $\left[\mathrm{CO}_{2}\right]$-lowering.

\begin{tabular}{|c|c|c|c|c|c|}
\hline & VP & $\begin{array}{c}{\left[\mathrm{CO}_{2}\right]-} \\
\text { lowering to } 10-15 \mathrm{ppm}\end{array}$ & $\begin{array}{c}{\left[\mathrm{CO}_{2}\right]-} \\
\text { lowering to } 150 \mathrm{ppm}\end{array}$ & $\begin{array}{c}\text { VP under } \\
{\left[\mathrm{CO}_{2}\right]=10-15 \mathrm{ppm}}\end{array}$ & $\begin{array}{l}\text { VP under far } \\
\text { red light }\end{array}$ \\
\hline Relative $E F(C)_{\text {initial, }} \%$ & $26.6 \pm 3.2$ & $25.5 \pm 4.9$ & $23.5 \pm 3.3$ & $57.2 \pm 3.8$ & $70.7 \pm 0.5$ \\
\hline Relative $E F(C)_{\max }, \%$ & $37.9 \pm 2.7^{*}$ & $59.9 \pm 3.5^{*}$ & $35.8 \pm 3.7^{*}$ & $69.5 \pm 3.0^{*}$ & $74.5 \pm 0.9 *$ \\
\hline Change in relative $E F(C), \%$ & $11.3 \pm 1.3^{*}$ & $34.5 \pm 3.0^{*}$ & $12.3 \pm 1.0^{*}$ & $12.3 \pm 1.6^{*}$ & $3.9 \pm 0.6^{*}$ \\
\hline
\end{tabular}

$* p<0.05$ compared with control, paired Student t-test $(n=9-17)$.

2002, 2004; Zivcak et al., 2013); however, the mechanisms of these connections remain unclear.

The simplest schema of PSI, based on Klughammer and Schreiber (1994) and Vredenberg and Bulychev (2010) and including $\mathrm{P}_{700}$ oxidation and $\mathrm{P}_{700}^{+}$reduction, was used here for analysis of photosynthetic response mechanisms (Figure 9). Using this schema, $E F(P S I I)$ and $E F(C)$ were described by Equations (10) and (11): 


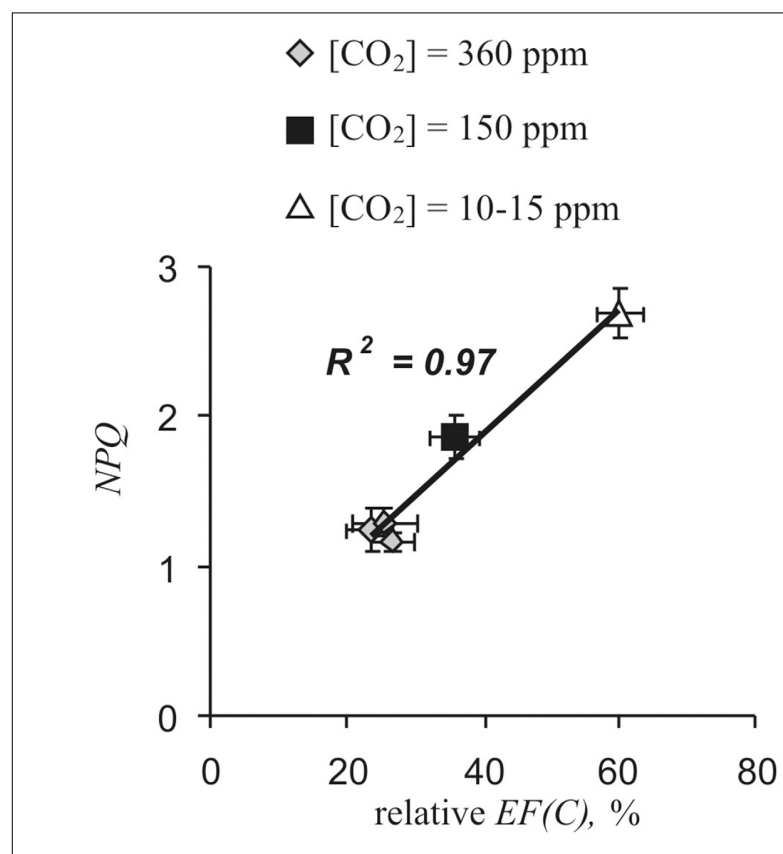

FIGURE 8 | Fluorescence non-photochemical quenching (NPQ) was plotted against relative cyclic electron flow [relative $E F(C)$ ] under different $\mathrm{CO}_{2}$ concentrations. Relative $E F(C)$ and $\mathrm{NPO}$ were taken from the Tables 1, 4 (unheated plants).

$$
\begin{aligned}
E F(P S I I) & =k_{L} \times \phi_{N D} \\
E F(C) & =k_{C} \times \phi_{N D}
\end{aligned}
$$

There are two possible mechanisms for the observed connection between increases in $\phi_{N D}$ and $E F(C)$ (Table 2). (i) Increased $k_{C}$ is the main mechanism for increasing cyclic electron flow induced by VP or $\left[\mathrm{CO}_{2}\right]$-lowering under control conditions. This can be caused by activation of any stage of cyclic electron flow, with the exception of $\mathrm{P}_{700}^{+}$reduction, and increased concentrations of reduced plastocyanin. In this case, $k_{C}$ increases contribute to transformation of $\mathrm{P}_{700}^{+}$into $\mathrm{P}_{700}$ and thereby lowers $\phi_{N D}$ (Figure 9). Thus, decreased $\phi_{N D}$, increased photosynthetic cyclic electron flow, and negative correlation between changes in $E F(C)$ and $\phi_{N D}$ must appear that are contrary to the present experimental results (Figures 4, 5, Tables 1, 2). (ii) Decreases in $k_{L}$ suppress transformation of $\mathrm{P}_{700}^{+}$into $\mathrm{P}_{700}$ and/or increases in $k_{h v}$ activate conversion of $\mathrm{P}_{700}$ into $\mathrm{P}_{700}^{+}$that then increases $\phi_{N D}$ (Figure 9). According to Equation (11), increased $\phi_{N D}$ must activate cyclic electron flow. As a result, $\phi_{N D}$ and $E F(C)$ increase and, in this case, a positive correlation between changes in $E F(C)$ and $\phi_{N D}$ should be observed. The second variant was in perfect accordance with the present experimental results. Thus, the following chain of events is supposed: $\mathrm{VP} \rightarrow \cdots \rightarrow \phi_{N D}$ increase $\rightarrow E F(C)$ growth.

Similar analysis can be employed for examining connections between increased $\phi_{N D}$ and reduced $E F(P S I I)$ (Figures 4, 5, Tables 1, 2). The positive influence of $k_{C}$ changes was not probable because increased $k_{C}$ decreases $\phi_{N D}$ (see above) and decreased $k_{C}$ decreases $E F(C)$ (Equation 11). Increased $k_{h v}$ appeared to

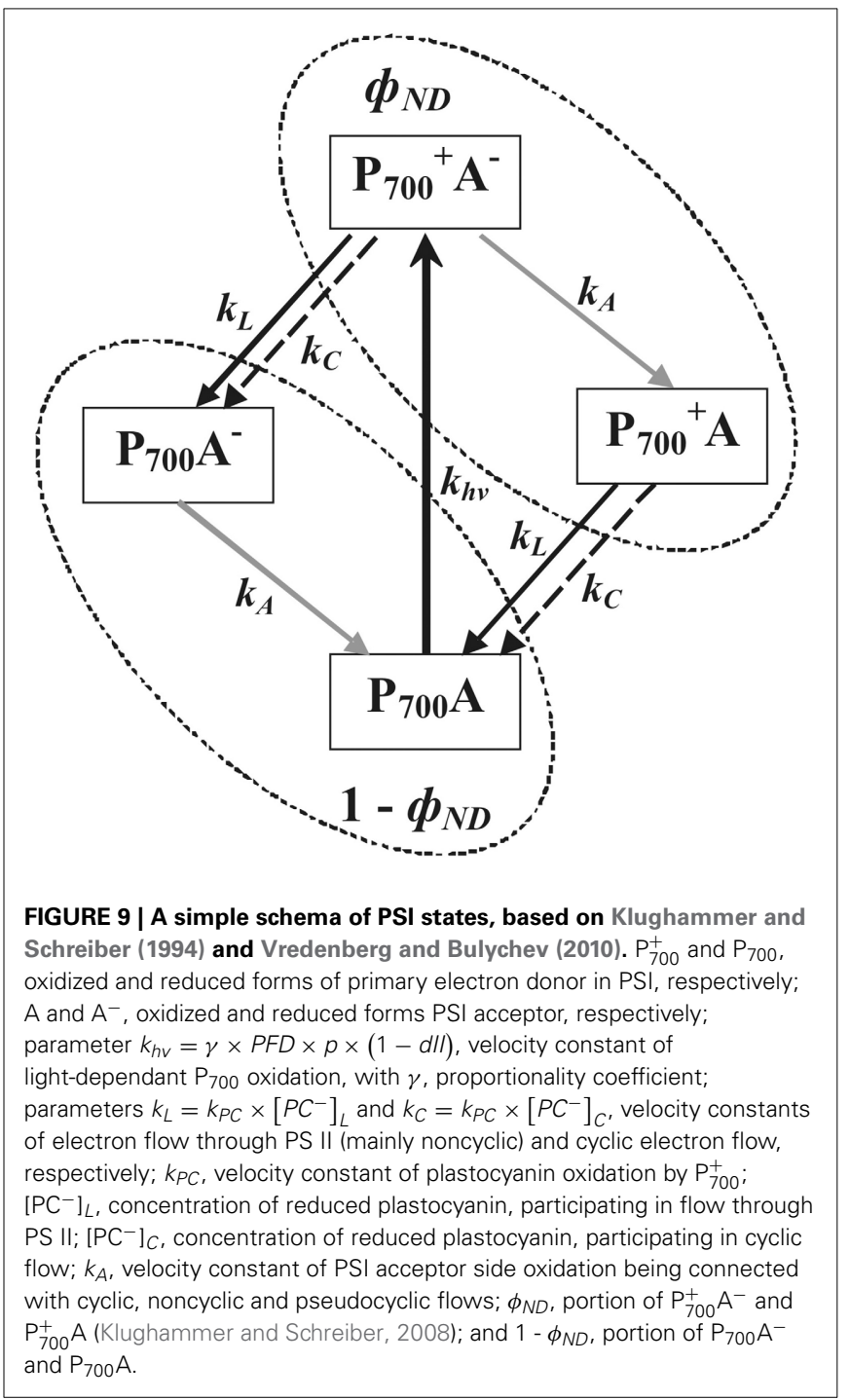

increase $\phi_{N D}$ (Figure 9); however, if $\phi_{N D}$ increased and $k_{L}$ was not changed, then $E F(P S I I)$ must increase (Equation 10), which is contrary to experimental results. Moreover, the main reason for $k_{h v}$ changes was modification of $d I I$, but $d I I$ was probably not affected by VP. Alternatively, decreased $k_{L}$ suppressed transformation of $\mathrm{P}_{700}^{+}$into $\mathrm{P}_{700}$ and increased $\phi_{N D}$ (Figure 9), while also lowering $E F(P S I I)$ (Equation 10). The $k_{L}$ decrease could have been caused by inactivation of any stage of noncyclic electron transport, which preceded PSI, and which induced decreased concentrations of reduced plastocyanin. This last variant was in a good accordance with the experimental results obtained here (decreased $E F(P S I I)$, increased $\phi_{N D}$, and negative correlation between changes in $E F(P S I I)$ and $\left.\phi_{N D}\right)$. Decreased $k_{L}$ reflected decreased electron flow from PSII. Thus, the chain of events was extended to yield: $\mathrm{VP} \rightarrow \ldots \rightarrow E F(P S I I)$ decrease $\rightarrow \phi_{N D}$ increase $\rightarrow E F(C)$ growth.

The present results indicate that decreased $E F(P S I I)$ reflects VP-induced lowering of $\phi_{P S I I}$ (Figure 4, Table 1). According to published data (Pavlovič et al., 2011; Sukhov et al., 2012, 2014a,b) and the present results, this decrease in $E F(P S I I)$ was mainly 


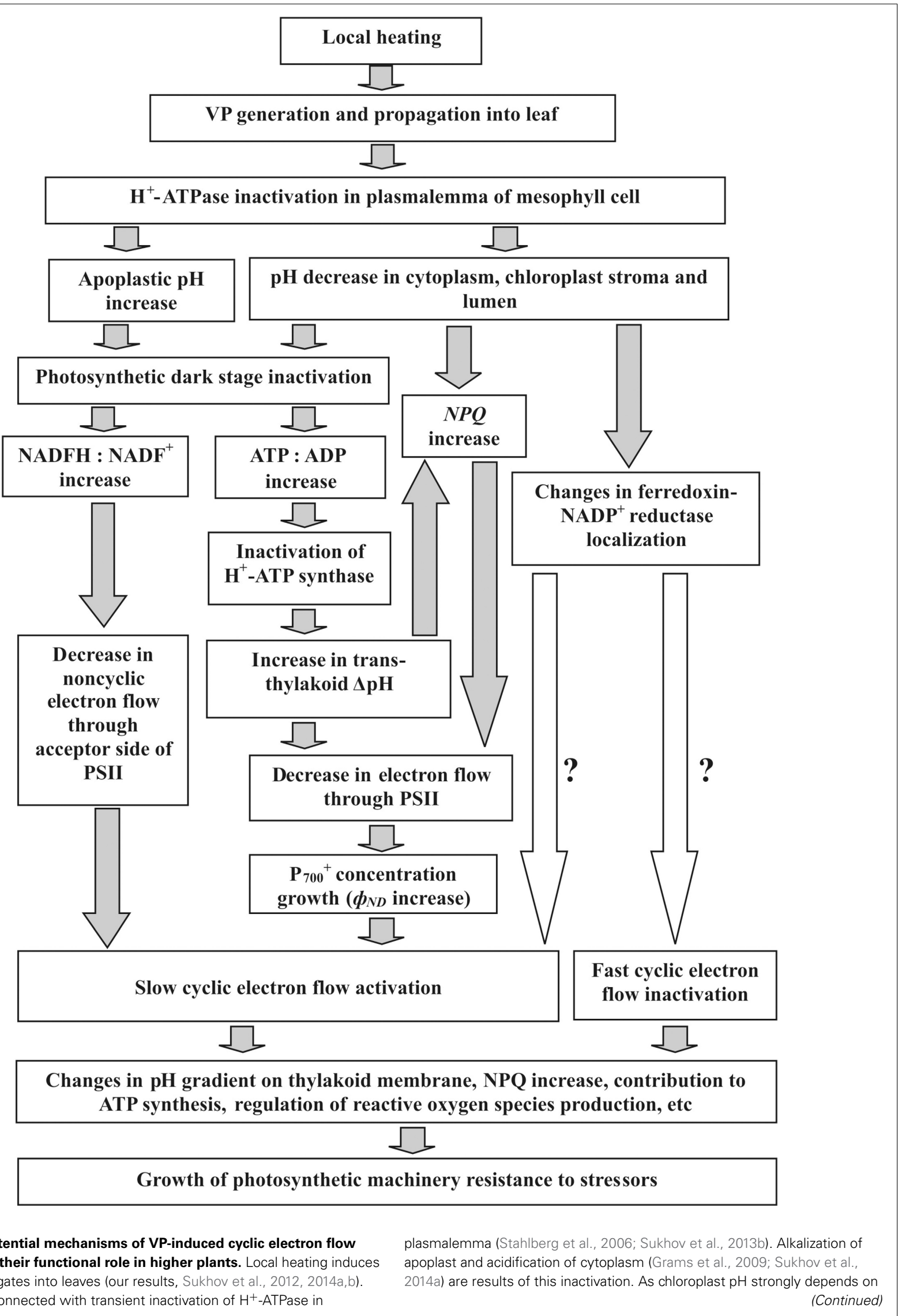




\section{FIGURE 10 | Continued}

external medium in chloroplast suspensions (Werdan et al., 1975), cytoplasmic acidification can reduce $\mathrm{pH}$ in chloroplasts. Alkalization of apoplast and acidification of cytoplasm can suppress $\mathrm{CO}_{2}$ influx from apoplast to cytoplasm and stroma, and reduce Calvin cycle activity (Bulychev et al., 2001; Grams et al., 2009; Sukhov et al., 2014a). Acidification of stroma essentially suppresses photosynthesis (Werdan et al., 1975) that might be connected with $\mathrm{pH}$-dependent Calvin cycle enzymes (Wolosiuk et al., 1993) and nonphotochemical energy dissipation in PSII (Müller et al., 2001). VP-induced photosynthetic dark stage suppression (our results, Sukhov et al., 2012, 2014a,b) inactivates $\mathrm{H}^{+}$-ATP synthase and increases trans-thylakoid $\Delta \mathrm{pH}$ (Pavlovič et al., 2011) that reduces electron flow through PSII (Schönknecht et al., 1995) and additionally stimulates NPQ (Müller et al., 2001). Increase of nonphotochemical energy dissipation in PSII (our results, Sukhov et al., 2014a) also decreases electron flow through PSII (our results). In turn, this increases $\mathrm{P}_{700}^{+}$concentration and, thereby, stimulates cyclic electron flow (our results). Alternatively, photosynthetic dark stage inactivation may increase NADFH:NADF+ (Pavlovič et al., 2011) that can also intensify cyclic electron flow. There is an additional VP-induced slow cyclic electron flow activation, which is connected with fast cyclic flow inactivation, and is not affected by electron flow through PSII (our results). pH-Dependent changes in ferredoxin-NADP ${ }^{+}$reductase localization (Alte et al., 2010; Benz et al., 2010) might participate in both additional activation and fast inactivation, because this enzyme possibly plays a role in cyclic electron flow (Joliot and Johnson, 2011). Finally, changes in cyclic electron flow might participate in electrical signal induced resistance of photosynthetic machinery to stressors (Retivin et al., 1999; Sukhov et al., 2014b). This might be because cyclic flow contributes to ATP synthesis, regulates oxygen species production, additionally increases $N P Q$, and keeps the PSI acceptor side oxidized, protecting it from damage (Joliot and Joliot, 2006; Rumeau et al., 2007; Zhang and Sharkey, 2009; Roach and Krieger-Liszkay, 2014). induced by photosynthetic dark stage inactivation. In support of this conclusion, changes in $A$ and $E F(P S I I)$ were strongly correlated and reduced $\mathrm{CO}_{2}$ assimilation rate induced by $\left[\mathrm{CO}_{2}\right]$ lowering decreased electron flow through PSII was similar to VP's effect. In addition, VP-induced EF(PSII) changes under low $\left[\mathrm{CO}_{2}\right]$ conditions were smaller than changes under control conditions. However, VP-induced EF(PSII) decreases were not absent under low $\left[\mathrm{CO}_{2}\right]$. Considering that decreased $A$ in these experiments $\left(-1.08 \pm 0.21 \mu \mathrm{mol} \cdot \mathrm{m}^{-2} \cdot \mathrm{s}^{-1}\right)$ was indistinguishable from a VP-induced respiration response $(-1.10 \pm$ $0.20 \mu \mathrm{mol} \cdot \mathrm{m}^{-2} \cdot \mathrm{s}^{-1}$, Sukhov et al., 2014a), it was concluded that VP could also have suppressed electron flow through PSII without photosynthetic dark stage inactivation. Increased NPQ was a potential mechanism for VP's influence on PSII because its response is not dependent on electrical signal-induced decrease of $\mathrm{CO}_{2}$ assimilation (Sukhov et al., 2014a). As a result, the following chain of events was proposed here: $\mathrm{VP} \rightarrow \ldots \rightarrow$ inactivation of photosynthetic dark stage and NPQ increase $\rightarrow E F(P S I I)$ decrease $\rightarrow \phi_{N D}$ increase $\rightarrow E F(C)$ increase.

VP-connected proton flux from apoplast to cytoplasm, stroma, and lumen is a possible mechanism for initial induction of a photosynthetic response, including decreased $\phi_{P S I I}$ (Grams et al., 2009; Sukhov et al., 2014a). It is known that VP generation is connected with transient $\mathrm{H}^{+}$-ATPase inactivation and proton influx (Stahlberg et al., 2006; Sukhov et al., 2013b), which changes intraand extracellular pH (Grams et al., 2009; Sukhov et al., 2014a). However, decreased intracellular $\mathrm{pH}$ can suppress PSII photosynthetic activity and induces NPQ (Grams et al., 2009; Bulychev et al., 2013a,b; Sukhov et al., 2013a, 2014a). Taking into account these facts, it can be proposed that $\mathrm{VP} \rightarrow \mathrm{H}^{+}$influx $\rightarrow$ inactivation of photosynthetic dark stage and NPQ growth $\rightarrow E F(P S I I)$ decrease $\rightarrow \phi_{N D}$ increase $\rightarrow E F(C)$ growth. Figure 10 shows this possible mechanism of VP influence on cyclic electron flow in more detail.

It should be noted that photosynthetic dark stage inactivation can increase NADFH:NADF ${ }^{+}$(Pavlovič et al., 2011) that decreases noncyclic electron flow through acceptor side of PSI and may stimulate cyclic electron flow. However, this process (decrease in $\mathrm{k}_{A}$ in Figure 9) induces increase in $\mathrm{P}_{700} \mathrm{~A}^{-}\left(\phi_{N A}\right)$ that was not observed in experiments with varied $\mathrm{CO}_{2}$ concentrations (Table 1). Thus, change in NADFH:NADF ${ }^{+}$in unlikely to be main mechanism of $E F(C)$ growth, but it can play minor role in the process.

VP-induced responses under far red light indicated that another mechanism of cyclic electron flow activation, not connected with noncyclic flow changes, also participated in the photosynthetic response. In this case, $E F(C)$ activation and decreased $\phi_{N D}$ were observed and correlation between these parameters was negative (Table 3). Considering Figure 9 and Equation (11), it was concluded that such effects could have been caused by increased $k_{C}$. The mechanism of $E F(C)$ activation was not clarified here, but the magnitude of the activation correlated with the magnitude of fast inactivation of cyclic electron flow; i.e., similar mechanisms for both processes were probable. It is known that $\mathrm{pH}$ decreases can change ferredoxin-NADP ${ }^{+}$reductase localization (Alte et al., 2010; Benz et al., 2010); in addition, reductase possibly participates in cyclic electron flow (Joliot and Johnson, 2011). Considering this information, it was speculated that stromal $\mathrm{pH}$ changes influenced ferredoxin-NADP ${ }^{+}$reductase localization and induced a two-stage $E F(C)$ response, including inactivation and subsequent activation of cyclic flow (Figure 7). VP-induced inactivation of the acceptor side of PSI, which was not connected with decreased photosynthetic dark stage activity (Sukhov et al., 2012) and can caused by changes in ferredoxin$\mathrm{NADP}^{+}$reductase localization (Sukhov et al., 2014a), supported this hypothesis.

Thus, VP increased cyclic electron flow in an absolute (Tables 1, 3) and relative (Table 3) manner. A physiological role for this response could have been connected with increased photosynthetic machinery resistance to environmental stressors. It is known that cyclic electron flow can maintain a high proton gradient on thylakoid membrane and, thereby, contributes to ATP synthesis and NPQ increases (Zhang and Sharkey, 2009; Joliot and Johnson, 2011). Also, cyclic electron flow protects PSI and can regulate reactive oxygen species production by photosynthetic electron transfer chain (Rumeau et al., 2007; Roach and KriegerLiszkay, 2014). It is known that electrical signals exert influence on the resistance of photosynthetic machinery to stressors in higher plants (Retivin et al., 1999; Sukhov et al., 2014b). In particular, VP increases PSI resistance to heating in pea (Sukhov et al., 2014b), and it was supposed here that VP-induced activation of cyclic electron flow participated in this increased resistance. 
Stimulation of NPQ is important mechanism of cyclic electron flow influence on photosynthetic machinery resistance to stressors (Munekage et al., 2002, 2004; Zhang and Sharkey, 2009; Joliot and Johnson, 2011). This stimulation was observed under moderate actinic light (about $200 \mu \mathrm{mol} \cdot \mathrm{m}^{-2} \cdot \mathrm{s}^{-1}$ ) (Munekage et al., 2002, 2004). Miyake et al. (2004, 2005) showed that NPQ was strongly depended on cyclic electron flow when $E F(P S I)$ / $E F(P S I I)>1.2-1.3$. Table 4 shows that VP activated relative $E F(C)$ from 27 to $38 \%$ in pea ( $E F(P S I) / E F(P S I)$ increased from 1.37 to 1.61 ), i.e., activation of cyclic electron flow can influence NPQ. Figure 8 shows that NPQ and relative $E F(C)$ were linearly connected that can be interpreted according to Miyake et al. $(2004,2005)$ as stimulation of NPQ by cyclic electron flow. Positive correlation between $N P Q$ and relative $E F(C)$ under control conditions also supports this hypothesis. Thus, it may be supposed that VP-induced cyclic electron flow activation stimulates NPQ and, thereby, increases of photosynthetic machinery resistance.

\section{ACKNOWLEDGMENT}

This work was supported by the Russian Scientific Fund (Project No. 14-26-00098).

\section{REFERENCES}

Allen, J. F. (2003). Cyclic, pseudocyclic and noncyclic photophosphorylation: new links in the chain. Trends Plant Sci. 8, 15-19. doi: 10.1016/S13601385(02)00006-7

Alte, F., Stengel, A., Benz, J. P., Petersen, E., Soll, J., Groll, M., et al. (2010). Ferredoxin:NADPH oxidoreductase is recruited to thylakoids by binding to a polyproline type II helix in a $\mathrm{pH}$-dependent manner. Proc. Natl. Acad. Sci. U.S.A. 107, 19260-19265. doi: 10.1073/pnas.1009124107

Benz, J. P., Stengel, A., Lintala, M., Lee, Y. H., Weber, A., Philippar, K., et al. (2010). Arabidopsis Tic62 and ferredoxin-NADP(H) oxidoreductase form lightregulated complexes that are integrated into the chloroplast redox poise. Plant Cell 21, 3965-3983. doi: 10.1105/tpc.109.069815

Berger, S., Papadopoulos, M., Schreiber, U., Kaiser, W., and Roitsch, T. (2004). Complex regulation of gene expression, photosynthesis and sugar levels by pathogen infection in tomato. Physiol. Plant. 122, 419-428. doi: 10.1111/j.13993054.2004.00433.x

Brenner, E. D., Stahlberg, R., Mancuso, S., Vivanco, J., Baluska, F., and Van Volkenburgh, E. (2006). Plant neurobiology: an integrated view of plant signaling. Trends Plant Sci. 11, 413-419. doi: 10.1016/j.tplants.2006. 06.009

Bukhov, N. G., Wiese, C., Neimanis, S., and Heber, U. (1999). Heat sensitivity of chloroplasts and leaves: leakage of protons from thylakoids and reversible activation of cyclic electron transport. Photosyn. Res. 59, 81-93.

Bulychev, A. A., Cherkashin, A. A., Rubin, A. B., Vredenberg, W. J., Zykov, V. S., and Müller, S. C. (2001). Comparative study on photosynthetic activity of chloroplasts in acid and alkaline zones of Chara corallina. Bioelectrochemistry 53, 225-232. doi: 10.1016/S0302-4598(01)00096-4

Bulychev, A. A., and Komarova, A. V. (2014). Long-distance signal transmission and regulation of photosynthesis in characean cells. Biochemistry (Moscow) 79, 273-281. doi: 10.1134/S0006297914030134

Bulychev, A. A., Komarova, A. V., and Rubin, A. B. (2013a). Propagation of photoinduced signals with the cytoplasmic flow along Characean internodes: evidence from changes in chloroplast fluorescence and surface $\mathrm{pH}$. Eur. Biophys. J. 42, 441-453. doi: 10.1007/s00249-013-0895-Z

Bulychev, A. A., Komarova, A. V., and Rubin, A. B. (2013b). Fluorescence transients in chloroplasts of Chara coralline cells during transmission of photoinduced signal with the streaming cytoplasm. Russ. J. Plant Physiol. 60, 33-40. doi: $10.1134 /$ S1021443712060039

Davies, E., and Stankovic, B. (2006). "Electrical signals, the cytoskeleton, and gene expression: a hypothesis on the coherence of the cellular responses to environmental insult," in Communication in Plants. Neuronal Aspects of Plant Life, eds
F. Baluška, S. Mancuso, and D. Volkmann (Berlin-Heidelberg: Springer-Verlag), 309-320.

Dziubinska, H. (2003). Ways of signal transmission and physiological role of electrical potential in plants. Acta Soc. Bot. Pol. 72, 309-318. doi: 10.5586/asbp. 2003.040

Felle, H. H., and Zimmermann, M. R. (2007). Systemic signaling in barley through action potentials. Planta 226, 203-214. doi: 10.1007/s00425-006-0458-y

Fromm, J., and Lautner, S. (2012). "Generation, transmission, and physiological effects of electrical signals in plants," in Plant Electrophysiology. Signaling and Responses, ed A. G. Volkov (Heidelberg-New York-Dordrecht-London: Springer), 207-232. doi: 10.1007/978-3-642-29110-4_8

Gallé, A., Lautner, S., Flexas, J., Ribas-Carbo, M., Hanson, D., Roesgen, J., et al. (2013). Photosynthetic responses of soybean (Glycine max L.) to heat-induced electrical signalling are predominantly governed by modifications of mesophyll conductance for $\mathrm{CO}_{2}$. Plant Cell Environ. 36, 542-552. doi: 10.1111/j.13653040.2012.02594.x

Grams, T. E. E., Lautner, S., Felle, H. H., Matyssek, R., and Fromm, J. (2009). Heat-induced electrical signals affect cytoplasmic and apoplastic $\mathrm{pH}$ as well as photosynthesis during propagation through the maize leaf. Plant Cell Environ. 32, 319-326. doi: 10.1111/j.1365-3040.2008.01922.x

Hogewoning, S. W., Wientjes, E., Douwstra, P., Trouwborst, G., van Ieperen, W., Croce, R., et al. (2012). Photosynthetic quantum yield dynamics: from photosystems to leaves. Plant Cell 24, 1921-1935. doi: 10.1105/tpc.112.097972

Huang, W., Yang, S. J., Zhang, S. B., Zhang, J. L., and Cao, K. F. (2012). Cyclic electron flow plays an important role in photoprotection for the resurrection plant Paraboea rufescens under drought stress. Planta 235, 819-828. doi: 10.1007/s00425-011-1544-3

Huang, W., Zhang, S. B., and Cao, K. F. (2011). Cyclic electron flow plays an important role in photoprotection of tropical trees illuminated at temporal chilling temperature. Plant Cell Physiol. 52, 297-305. doi: 10.1093/pcp/pcq166

Joliot, P., and Johnson, G. N. (2011). Regulation of cyclic and linear electron flow in higher plants. Proc. Natl. Acad. Sci. U.S.A. 108, 13317-13322. doi: $10.1073 /$ pnas. 1110189108

Joliot, P., and Joliot, A. (2006). Cyclic electron flow in C3 plants. Biochim. Biophys. Acta 1757, 362-368. doi: 10.1016/j.bbabio.2006.02.018

Katicheva, L., Sukhov, V., Akinchits, E., and Vodeneev, V. (2014). Ionic nature of burn-induced variation potential in wheat leaves. Plant Cell Physiol. 55, 1511-1519. doi: 10.1093/pcp/pcu082

Klughammer, C., and Schreiber, U. (1994). An improved method, using saturating light pulses, for the determination of photosystem I quantum yield via $\mathrm{P} 700^{+}$absorbance changes at $830 \mathrm{~nm}$. Planta 192, 261-268.

Klughammer, C., and Schreiber, U. (2008). Saturation pulse method for assessment of energy conversion in PS I. PAM Application Notes 1, 11-14. Available online at: http://www.walz.com/downloads/pan/PAN07002.pdf

Koziolek, C., Grams, T. E. E., Schreiber, U., Matyssek, R., and Fromm, J. (2004). Transient knockout of photosynthesis mediated by electrical signals. New Phytol. 161, 715-722. doi: 10.1111/j.1469-8137.2004.00985.x

Krupenina, N. A., and Bulychev, A. A. (2007). Action potential in a plant cell lowers the light requirement for non-photochemical energy-dependent quenching of chlorophyll fluorescence. Biochim. Biophys. Acta 1767, 781-788. doi: 10.1016/j.bbabio.2007.01.004

Makino, A., Miyake, C., and Yokota, A. (2002). Physiological functions of the waterwater cycle (Mehler reaction) and the cyclic electron flow around PSI in rice leaves. Plant Cell Physiol. 43, 1017-1026. doi: 10.1093/pcp/pcf124

Mancuso, S., and Mugnai, S. (2006). "Long-distance signal transmission in trees," in Communication in Plants. Neuronal Aspects of Plant Life, eds F. Baluška, S. Mancuso, and D. Volkmann (Berlin-Heidelberg: Springer-Verlag), 333-349.

Maxwell, K., and Johnson, G. N. (2000). Chlorophyll fluorescence - a practical guide. J. Exp. Bot. 51, 659-668. doi: 10.1093/jexbot/51.345.659

Miyake, C., Miyata, M., Shinzaki, Y., and Tomizawa., K. (2005). $\mathrm{CO}_{2}$ response of cyclic electron flow around PSI (CEF-PSI) in tobacco leaves-relative electron fluxes through PSI and PSII determine the magnitude of non-photochemical quenching (NPQ) of Chl fluorescence. Plant Cell Physiol. 46, 629-637. doi: $10.1093 / \mathrm{pcp} / \mathrm{pci067}$

Miyake, C., Shinzaki, Y., Miyata, M., and Tomizawa, K. (2004). Enhancement of cyclic electron flow around PSI at high light and its contribution to the induction of non-photochemical quenching of chl fluorescence in intact leaves of tobacco plants. Plant Cell Physiol. 45, 1426-1433. doi: 10.1093/pcp/ pch163 
Miyake, C., and Yokota, A. (2000). Determination of the rate of photoreduction of $\mathrm{O}_{2}$ in the water-water cycle in watermelon leaves and enhancement of the rate by limitation of photosynthesis. Plant Cell Physiol. 41, 335-343. doi: $10.1093 / \mathrm{pcp} / 41.3 .335$

Müller, P., Li, X.-P., and Niyogi, K. K. (2001). Non-photochemical quenching. A response to excess light energy. Plant Physiol. 125, 1558-1566. doi: 10.1104/pp.125.4.1558

Munekage, Y., Hashimoto, M., Miyake, C., Tomizawa, K., Endo, T., Tasaka, M., et al. (2004). Cyclic electron flow around photosystem I is essential for photosynthesis. Nature 429, 579-582. doi: 10.1038/nature02598

Munekage, Y., Hojo, M., Meurer, J., Endo, T., Tasaka, M., and Shikanai, T. (2002). PGR5 is involved in cyclic electron flow around photosystem I and is essential for photoprotection in Arabidopsis. Cell 110, 361-371. doi: 10.1016/S00928674(02)00867-X

Pavlovič, A. (2012). "The effect of electrical signals on photosynthesis and respiration," in Plant Electrophysiology. Signaling and Responses, ed A. G. Volkov (Heidelberg-New York-Dordrecht-London: Springer), 33-62 doi: 10.1007/9783-642-29110-4_2

Pavlovič, A., Slovákov,á, L., Pandolfi, C., and Mancuso, S. (2011). On the mechanism underlying photosynthetic limitation upon trigger hair irritation in the carnivorous plant Venus flytrap (Dionaea muscipula Ellis). J. Exp. Bot. 62, 1991-2000. doi: 10.1093/jxb/erq404

Retivin, V. G., Opritov, V. A., and Fedulina, S. B. (1997). Generation of action potential induces preadaptation of Cucurbita pepo L. stem tissues to freezing injury. Russ. J. Plant Physiol. 44, 432-442.

Retivin, V. G., Opritov, V. A., Lobov, S. A., Tarakanov, S. A., and Khudyakov, V. A. (1999). Changes in the resistance of photosynthesizing cotyledon cells of pumpkin seedlings to cooling and heating, as induced by the stimulation of the root system with $\mathrm{KCl}$ solution. Russ. J. Plant Physiol. 46, 689-696.

Roach, T., and Krieger-Liszkay, A. (2014). Regulation of photosynthetic electron transport and photoinhibition. Curr. Protein Pept. Sci. 15, 351-362. doi: 10.2174/1389203715666140327105143

Rumeau, D., Peltier, G., and Cournac, L. (2007). Chlororespiration and cyclic electron flow around PSI during photosynthesis and plant stress response. Plant Cell Environ. 30, 1041-1051. doi: 10.1111/j.1365-3040.2007.01675.x

Schönknecht, G., Neimanis, S., Katona, E., Gerst, U., and Heber, U. (1995). Relationship between photosynthetic electron transport and $\mathrm{pH}$ gradient across the thylakoid membrane in intact leaves. Proc. Natl. Acad. Sci. U.S.A. 92, 12185-12189. doi: 10.1073/pnas.92.26.12185

Stahlberg, R., Robert, E., Cleland, R. E., and van Volkenburgh, E. (2006). "Slow wave potentials - a propagating electrical signal unique to higher plants," in Communication in Plants. Neuronal Aspects of Plant Life,eds F. Baluška, S. Mancuso, and D. Volkmann (Berlin-Heidelberg: Springer-Verlag), 291-309.

Sukhov, V., Akinchits, E., Katicheva, L., and Vodeneev, V. (2013b). Simulation of variation potential in higher plant cells. J. Membr. Biol. 246, 287-296 doi: 10.1007/s00232-013-9529-8

Sukhov, V., Orlova, L., Mysyagin, S., Sinitsina, J., and Vodeneev, V. (2012). Analysis of the photosynthetic response induced by variation potential in geranium. Planta 235, 703-712. doi: 10.1007/s00425-011-1529-2

Sukhov, V., Sherstneva, O., Surova, L., Katicheva, L., and Vodeneev, V. (2014a). Proton cellular influx as a probable mechanism of variation potential influence on photosynthesis in pea. Plant Cell Environ. 37, 2532-2541. doi: $10.1111 /$ pce. 12321

Sukhov, V. S., Sherstneva, O. N., Surova, L. M., Rumiantsev, E. A., and Vodeneev, V. A. (2013a). Influence of a variation potential on photosynthesis in pumpkin seedlings (Cucurbita pepo L.). Biophysics 58, 361-365. doi: $10.1134 /$ S0006350913030184

Sukhov, V., Surova, L., Sherstneva, O., and Vodeneev, V. (2014b). Influence of variation potential on resistance of the photosynthetic machinery to heating in pea. Physiol. Plant. 152, 773-783. doi: 10.1111/ppl.12208

Sukhov, V., and Vodeneev, V. (2009). A mathematical model of action potential in cells of vascular plants. J. Membr. Biol. 232, 59-67. doi: 10.1007/s00232-0099218-9
Trebacz, K., Dziubinska, H., and Krol, E. (2006). "Electrical signals in long-distance communication in plants," in Communication in Plants. Neuronal Aspects of Plant Life, eds F. Baluška, S. Mancuso, and D. Volkmann (Berlin-Heidelberg: Springer-Verlag), 277-290.

Vodeneev, V. A., Akinchits, E. K., Orlova, L. A., and Sukhov, V. S. (2011). The role of $\mathrm{Ca}^{2+}, \mathrm{H}^{+}$, and $\mathrm{Cl}^{-}$ions in generation of variation potential in pumpkin plants. Russ. J. Plant Physiol. 58, 974-981. doi: 10.1134/S10214437110 50256

Vodeneev, V., Orlova, A., Morozova, E., Orlova, L., Akinchits, E., Orlova, O., et al. (2012). The mechanism of propagation of variation potentials in wheat leaves. J. Plant Physiol. 169, 949-954. doi: 10.1134/S102144371 1050256

Volkov, A. G. (2000). Green plants: electrochemical interfaces. J. Electroanal. Chem. 483, 150-156. doi: 10.1016/S0022-0728(99) 00497-0

Volkov, A. G., Adesina, T., Markin, V. S., and Jovanov, E. (2008). Kinetics and mechanism of Dionaea muscipula trap closing. Plant Physiol. 146, 694-702. doi: 10.1104/pp.107.108241

Von Caemmerer, S., Farquhar, G., and Berry, J. (2009). "Biochemical model of $\mathrm{C}_{3}$ photosynthesis, in Photosynthesis In Silico. Understanding Complexity from Molecules to Ecosystems, eds A. Laisk, L. Nedbal, and Govindjee (Dordrecht: Springer), 209-230.

Von Caemmerer, S., and Farquhar, G. D. (1981). Some relationships between the biochemistry of photosynthesis and the gas exchange of leaves. Planta 153, 376-387. doi: 10.1007/BF00384257

Vredenberg, W. J., and Bulychev, A. A. (2010). Photoelectrochemical control of the balance between cyclic- and linear electron transport in photosystem I. Algorithm for $\mathrm{P}^{+} 00^{+}$induction kinetics. Biochim. Biophys. Acta 1797, 1521-1532. doi: 10.1016/j.bbabio.2010. 03.019

Werdan, K., Heldt, H. W., and Milovancev, M. (1975). The role of $\mathrm{pH}$ in the regulation of carbon fixation in the chloroplast stroma. Studies on $\mathrm{CO}_{2}$ fixation in the light and dark. Biochim. Biophys. Acta 396, 276-292. doi: 10.1016/00052728(75)90041-9

Wolosiuk, R. A., Ballicora, M. A., and Hagelin, K. (1993). The reductive pentose phosphate cycle for photosynthetic $\mathrm{CO}_{2}$ assimilation: enzyme modulation. FASEB J. 7, 622-637.

Zhang, R., and Sharkey, T. D. (2009). Photosynthetic electron transport and proton flux under moderate heat stress. Photosyn. Res. 100, 29-43. doi: 10.1007/s11120009-9420-8

Zivcak, M., Brestic, M., Balatova, Z., Drevenakova, P., Olsovska, K., Kalaji, H. M., et al. (2013). Photosynthetic electron transport and specific photoprotective responses in wheat leaves under drought stress. Photosyn. Res. 117, 529-546. doi: $10.1007 /$ s11120-013-9885-3

Conflict of Interest Statement: The authors declare that the research was conducted in the absence of any commercial or financial relationships that could be construed as a potential conflict of interest.

Received: 23 September 2014; accepted: 11 December 2014; published online: 07 January 2015.

Citation: Sukhov V, Surova L, Sherstneva O, Katicheva L and Vodeneev V (2015) Variation potential influence on photosynthetic cyclic electron flow in pea. Front. Plant Sci. 5:766. doi: 10.3389/fpls.2014.00766

This article was submitted to Plant Biophysics and Modeling, a section of the journal Frontiers in Plant Science.

Copyright (C) 2015 Sukhov, Surova, Sherstneva, Katicheva and Vodeneev. This is an open-access article distributed under the terms of the Creative Commons Attribution License (CC BY). The use, distribution or reproduction in other forums is permitted, provided the original author(s) or licensor are credited and that the original publication in this journal is cited, in accordance with accepted academic practice. No use, distribution or reproduction is permitted which does not comply with these terms. 